Full length article

\title{
Effects of an interculturally enriched collaboration script on student attitudes, behavior, and learning performance in a CSCL environment
}

\author{
Vitaliy Popov $^{\mathrm{a}, *}$, Harm J.A. Biemans ${ }^{\mathrm{a}}$, Karen P.J. Fortuin ${ }^{\mathrm{b}}$, Arnold J.H. van Vliet $^{\mathrm{b}}$, \\ Gijsbert Erkens ${ }^{c}$, Martin Mulder ${ }^{a}$, Jos Jaspers ${ }^{c}$, Yaoran Li $^{\mathrm{d}}$
}

\footnotetext{
${ }^{\mathrm{a}}$ Education and Learning Sciences Group, Wageningen University, the Netherlands

${ }^{\mathrm{b}}$ Environmental Systems Analysis Group, Wageningen University, the Netherlands

${ }^{\mathrm{c}}$ Department of Educational Sciences, Utrecht University, the Netherlands

${ }^{\mathrm{d}}$ Jacobs Institute for Innovation in Education, School of Leadership and Education Sciences, University of San Diego, USA
}

\section{A R T I C L E I N F O}

\section{Keywords:}

Collaborative learning

Computer-supported collaborative learning

Cultural diversity

Multicultural student group work

International students

Interculturally enriched collaboration script

\begin{abstract}
A B S T R A C T
People increasingly collaborate with others across cultures and distances with the help of technology. Bridging individuals via technology does not, however, ensure that the cultures of the individuals involved are similarly bridged. This study introduced an interculturally enriched collaboration script (IECS) to foster collaboration and to bridge intercultural differences when students were working in a computer-supported collaborative learning (CSCL) environment. A randomized, two group, pretest-posttest research design was used to compare the effects of the IECS with the effects of a general collaboration script (CS). The outcome variables were student attitudes towards online collaboration, online collaborative learning behavior, and learning performance of the culturally heterogeneous groups working in the CSCL environment. A total of 74 MSc students representing 22 countries worked in dyads on the environmental problem of biodiversity collapse. The IECS positively affected student attitudes towards online collaboration and their online collaborative learning behavior but not their learning performance. The IECS can thus be used to improve collaborative learning processes across cultures and distance in education.
\end{abstract}

\section{Introduction}

Educators as well as industry recognize collaboration as an "anchoring skill" (Wallender, 2014) - a skill upon which other skills are built (e.g., Adler, Heckscher, \& Prusak, 2011; P21, 2014). Organizations frequently use interdisciplinary teams to carry out complex tasks in order to innovate and stay competitive (Lovelace et al., 2001; Tancig, 2009). The Organization for Economic Cooperation and Development (OECD, 2015) recently introduced the PISA test of collaborative problem-solving in schools around the world. Thus, given collaboration's centrality, developing effective instructional strategies to support high-quality collaboration between students certainly ranks as one of the crucial challenges facing education and the world of work (Fischer, Kollar, Stegmann, \& Wecker, 2013; Hod, Sagy, \& Kali, 2018).

\footnotetext{
* Corresponding author at: Jacobs Institute for Innovation in Education, School of Leadership and Education Sciences, University of San Diego, Mother Rosalie Hill Hall, Room 259, 5998 Alcalá Park, San Diego, CA 92110-2492, USA.

E-mail address: vpopov@sandiego.edu (V. Popov).
} 
Today, people increasingly collaborate with others across cultures and distances with the help of technology in a range of fields. In education, many universities are introducing collaborative technologies, such as computer-supported collaborative learning (CSCL), to better prepare their students for the professional world. CSCL is often considered as an effective pedagogical approach beneficial for both group and individual learning (Erkens, Jaspers, Prangsma, \& Kanselaar, 2005; Stahl, 2017). In CSCL, two or more learners collaborate via the computer to solve problems or co-construct knowledge. This kind of learning entails the collaborative sensemaking and thus the articulation and sharing of ideas to be built upon by the collaborating partners (Prinsen, Volman, \& Terwel, 2007). In other words, students learn when they engage in a coordinated effort to jointly solve a problem by first eliciting one's own knowledge, then discussing the contributions with peers and finally building a consensus, shared understanding of the knowledge domain.

The introduction of CSCL, specifically among culturally diverse groups of students, creates both benefits and challenges. Among the benefits are the sharing of culturally diverse knowledge, development of the social, cognitive, and perspective-taking abilities of students, and hands-on preparation for working in an international climate (Walther, 1997). Among the challenges are the coordination of different attitudes, styles of communication, and patterns of behaving - all competing for effective expression (Kim \& Bonk, 2002; MacLeod, Yang, \& Xiang, 2017; Uzuner, 2009). Bridging learners via technology does not ensure that the cultures of the individuals engaged in collaboration are similarly bridged (Fussell \& Setlock, 2014). With culturally heterogeneous student groups becoming increasingly the baseline case rather than the exception, it is important to know how cultural differences can, at the very least, be accommodated and perhaps even leveraged effectively to promote learning. Therefore, the problem statement of the present study is how culturally diverse student groups can be supported during CSCL to bridge cultural differences and, thus, to attain the potential rewards of working in teams online.

In CSCL research, "scripting" has been found to be of value to promote collaborative learning (e.g., Fischer et al., 2013). So-called "collaboration scripts" for use in CSCL environments can be viewed as instructional support to guide students on what to do, what roles to play, and what sequences of activities to perform during a learning task (Carmien, Kollar, Fischer, \& Fischer, 2007). Collaboration scripts are intended to "promote productive interactions by designing the environment such that suggestions of different degrees of coercion are made to the collaborating students, engaging them in specific activities that otherwise might not occur" (Weinberger, 2011, p. 190). Yet, we have little knowledge of how collaboration scripts can be designed to help culturally diverse groups of students during CSCL (Gu, Wang, \& Mason, 2017; Weinberger, Clark, Hakkinen, Tamura, \& Fischer, 2007).

One way to do this might be through including additional culture-specific elements in the CSCL script and to design an interculturally enriched collaboration script (IECS) - a script with special attention to the unique cultural backgrounds of the different participants in the CSCL environment. The results obtained from a small-sample, exploratory study (Popov, Biemans, Kuznetsov, \& Mulder, 2014) showed that an IECS with its tailored instructions on how to approach a collaborative partner and engage in a collaborative discourse could positively affect student attitudes towards online collaboration, their online collaborative behavior, and their learning performance. However, more extensive research with a larger sample appeared to be needed to shed more light on the learning effects of using an IECS in culturally diverse CSCL groups.

The objective of the present study was therefore to further design, implement, and evaluate an Interculturally-Enriched Collaboration Script (IECS) that is tailored to the diverse cultural backgrounds of students working in culturally heterogeneous groups in a CSCL environment. The IECS was developed on the basis of previous research concerned with the use of collaboration scripts for CSCL and intercultural learning (e.g., Cox, Lobel, \& McLeod, 1991; Rummel \& Spada, 2005; Vatrapu \& Suthers, 2007; Weinberger et al., 2007; Weinberger, Marttunen, Laurinen, \& Stegmann, 2013). Classifying cultures in terms of their individualist and collectivist characteristics (based on research by Hofstede, Hofstede, and Minkov (2010)) and identifying those elements that are needed for an Interculturally-Enriched Collaboration Script (IECS) to be tailored to the individualist and collectivist cultural predispositions of students working collaboratively in a CSCL environment was adopted as the approach used in this study.

\section{Theoretical background}

\subsection{CSCL and the influence of culture on attitudes, behavior, and learning performance}

We know from previous research that culture influences individuals' social behavior (Hampden-Turner \& Trompenaars, 1997; Hofstede, 1997; House et al., 2004), attitudes towards online collaboration (Zhu, 2009, 2013), communication (Hall, 1990), cognitive processes (Nisbett \& Norenzayan, 2002; Ross, 2004), computer-mediated communication (Ess \& Sudweeks, 2005), online learning and asynchronous learning (e.g., Morse, 2003; Shi, Frederiksen, \& Muis, 2013; Uzuner, 2009), but we do not have ground rules for promoting online collaborative learning in groups that are culturally diverse. When cultural influences are not sufficiently articulated and integrated in a collaborative learning situation, students may experience misunderstandings that hamper the interaction, relationships among group members, and in the long run the quality of group work (Popov et al., 2012; Popov, Biemans, Brinkman, Kuznetsov, \& Mulder, 2013; Popov, Noroozi, et al., 2014).

There are three primary areas of research regarding the relationship between students' cultural backgrounds and learning in online collaborative learning environments. These studies have focused mostly on: (1) differences in how students from different cultural backgrounds perceive online group processes (e.g., Al-Harthi, 2005; Anakwe \& Christensen, 1999; Thompson \& Ku, 2005; Yumiko, Yukihiro, \& Pitagan, 2018); (2) how the linguistic and cultural backgrounds of collaborative partners impact their actual actions/behaviors/engagement in online collaborative situations (e.g., Kim \& Bonk, 2002; Lim \& Liu, 2006; Oetzel, 2001; Sandel, Buttny, \& Varghese, 2018); and (3) differences in students' motivation with respect to online collaborative learning environments (MacLeod et al., 2017; Wang, 2007). The majority of these studies operationalized culture either by connecting culture to nationality 
and/or ethnic origin (usually in cross-cultural comparison studies), or by applying various classifications of culture.

Collaborative learning occurs when students are actively engaged in the context of the current learning situation by explicit or implicit collaborative actions and conversational exchanges. These actions and discourse activities are influenced by one's "schemata of interpretation" - ways of explaining the society around us - social and content knowledge resulting from previous experiences, i.e. the transformation of socially shared activities that were internalized by an individual over time (Duffy \& Cunningham, 1996; Sweller, 1988). An individual relies on these previously constructed schemata when collaborating in interactive groups, namely social schemata guide how collaborative learning groups are expected to function within a particular cultural context, and content schemata navigate how to organize and perform learning tasks, reason, and negotiate meaning with one another in a group within a contextual framework (Frederiksen, 1999; Shi et al., 2013). Students differ in how they collaborate and comply with the activities required for collaboration (Rummel \& Spada, 2005).

Student attitudes towards online collaboration have been found to be one of the key determinants of the success of educational activities requiring online collaboration (So \& Brush, 2008; Zhu, 2009). Attitudes towards online collaboration can be defined as learners' social schemata governing their perspectives, feelings, and expectations with regard to online collaboration and, thus, influencing their learning (So \& Brush, 2008). Culture can be seen to influence the way in which individuals perceive learning and construct knowledge (Dai, 2019; Woodrow, 2001). Put differently, students' engagement in learning is influenced by personal experiences within particular cultural contexts (Zhu, 2013; Zhu, Valcke, Schellens, \& Li, 2009). The study, conducted by Nistor, Lerche, Weinberger, Ceobanu, and Heymann (2014) among nearly 3000 participants from Germany and Romania, showed the impact of national cultural differences on participants' attitudes towards educational technology. Romanians have a significantly more positive attitude, higher anxiety, and a stronger intention to use educational technology than Germans. The study by Zhu et al. (2009) examined cultural differences in the perception of computer-supported collaborative learning between Chinese and Flemish university students. They found that the Flemish students were more prone to group discussions, critical thinking, problem solving, and getting/giving help in the actual learning environment, whereas the Chinese group adopted a more negative attitude towards the social-constructivist e-learning environment. This study revealed a significant impact of the variable culture regarding the adoption of learning beliefs, critical thinking, and peer learning.

Similarly, Wang (2007) compared the perceptions of online collaborative learning and the comfort level within teacher-student interactions for students from China, the U.S.A., and Korea, and they found the participation of Korean and Chinese students in online discussions to mainly depend on course requirements. In contrast, the American students reported liking the connection with their peers and the Korean students exhibited less of a preference for online collaborative learning than the American and Chinese students. It has been suggested by a number of studies that students from individualist cultures are likely to see the collaborative learning environment as a medium to jointly identify problems and discuss conflicts in knowledge beliefs (Economides, 2008; Mittelmeier, Rienties, Tempelaar, \& Whitelock, 2018; Oetzel, Ting-Toomey, Yokochi, Masumoto, \& Takai, 2000; Vatrapu \& Suthers, 2007). Students from collectivist cultures, in contrast, are more likely to view the collaborative learning environment as a place to share information and explanations (Frambach, Driessen, Beh, \& van der Vleuten, 2014; Vatrapu \& Suthers, 2007).

Student attitudes towards online collaboration may influence their learning behaviors. While accomplishing a task collaboratively students from various cultures differ in terms of their procedural knowledge of how to collaborate and learn together (Cox et al., 1991; Weinberger et al., 2007). Previous research suggests that collaborative learning behaviors are integral activities of joint problem-solving, and group composition has been found to play a crucial role in such collaboration (Zhu, 2009). For example, Shi et al. (2013) investigated self-regulated learning actions (i.e., regulation and evaluation processes of one's own learning and behavior) of students who worked in dyads consisting of Chinese, Canadian, or mixed Chinese-Canadian in a face-to-face problem-based learning environment using a computer tutor program. Their study revealed that Canadian dyads were more likely to display individually-oriented actions, such as individual opinions or disagreements, compared to Chinese dyads. Besides, the Chinese students in the mixed-culture dyads placed a greater emphasis on socially-oriented actions, such as concerns about the opinions of and benefits for others, in their interactions with their Canadian partners.

A number of studies have demonstrated that mixed-culture group members are often challenged by process losses due to misunderstandings and coordination difficulties when working together. For example, Nguyen and Fussel (2012) examined students reported learning experiences and communication problems when they collaborated in mixed- and same-culture groups (i.e. American and Chinese participants) using Instant Messaging. The results showed that working in a culturally mixed groups resulted in a more negative perception of collaborative learning, mismatched communication styles, differences in conversational focus, feelings of annoyance, and relationship-building issues.

Similarly, Serçe, Swigger, Alpaslan, Brazile, Dafoulas, and Lopez (2011) conducted a study in three global virtual teams composed of students from Turkey, US, and Panama and found that the students from Panama exhibited higher proportions of social interaction and planning behaviors than the students from US and Turkey. In another case, when Kim and Bonk (2002) investigated the online collaborative behavior of Finnish, American, and Korean undergraduate pre-service teachers in web-based conferences, they found distinct patterns of online collaborative behavior: American and Finish students showed more task-oriented behavior, while Korean students showed more contextually driven and relationship-oriented behavior.

Finally, research suggests that the learning gains of individual students or groups of students from collaboration are also shaped (i.e., mediated) by their attitudes towards collaboration and their behavior during the collaborative learning activity (e.g., Kim \& Bonk, 2002; Lim \& Liu, 2006; Lizzio, Wilson, \& Simons, 2002). Successfully solving collaborative problems requires students to actively engage in a process to make sense of the subject matter by articulating relevant concepts, considering multiple perspectives, and discussing alternative solutions to the problem (Slof, Erkens, Kirschner, Jaspers, \& Janssen, 2010). Early CSCL research focused on the quality of individual learning results and/or collaborative learning products but often overlooked the fact that the outcome is 
mediated by the quality of the group learning process itself (Lim \& Liu, 2006). The many social and cultural factors that can significantly influence the interaction process have yet to be taken into account when studying CSCL (Weinberger et al., 2007). And there is very little research comparing learning performances of students from different cultures when working together in a CSCL context (see for notable exceptions Zhu et al., 2009, Shi et al., 2013, and Vatrapu, 2008).

The next section presents approaches and conceptual models for understanding culturally diverse CSCL student groups, and examines Hofstede's (1991) Individualist - Collectivist (I-C) dimension to describe what appear to be culture-based differences in CSCL processes.

\subsection{Conceptual models to operationalize culture}

A student's unique patterns of thinking, feeling, and acting in a collaborative learning situation may be influenced by his or her previous experience within specific cultural contexts. Hofstede (1991) and Triandis (1995) have argued that an individual's learned patterns of thinking, feeling, and interacting but also basic assumptions about the nature of the world perception are influenced by cultural context and the shared attributes, cognitive structures, and knowledge of a group of interconnected individuals. On the basis of shared attributes and cultural knowledge, the following two cultural orientations have been distinguished by these authors: collectivism or an orientation towards the collective goal of a group and individualism or an orientation towards individual goals rather than group goals or the goals of others in a group. In terms of collaborative learning, cultural background can thus influence one's understanding of the required collaborative processes and perceptions of the types of actions that are required and likely to be effective in a given learning situation (e.g., Lal, 2002; Markus \& Kitayama, 1991; Woodrow, 2001). Individualists focus on their own intentions and goals, and they tend to have relatively more opinions independent of group members than collectivists. Collectivists, in contrast, focus on shared group goals and tend to conform to the group.

The Individualist - Collectivist (I-C) cultural dimension as introduced by Hofstede (1991) has been widely used to describe what appear to be culture-based differences in collaborative group processes (e.g., Cox et al., 1991; Goncale \& Staw, 2006; Oetzel, 2001). Research replicating and supporting the robustness and validity of Hofstede's (1991) cultural value framework is large in scope and quantity, exceeding 5000 citations in the Web of Science (Taras, Rowney, \& Steel, 2009). Sondergaard (1994) analyzed 61 replications of Hofstede's cultural dimensions and stated that the majority of replications supported the existence of the dimensions. The I-C dimension has similarly been used to investigate the functioning of culturally diverse students involved in online learning environments and the results attained during the three phases of a collaborative problem-solving learning process as summarized in Table 1.

As stated above, collaborative problem solving is often regarded as a sequenced process, usually including the following three

Table 1

Summary of differences found in orientations towards the collaborative learning process.

\begin{tabular}{|c|c|c|c|}
\hline $\begin{array}{l}\text { Phases in the } \\
\text { collaborative problem- } \\
\text { solving process }\end{array}$ & Individualists & Collectivists & Literature sources \\
\hline \multirow{7}{*}{$\begin{array}{l}\text { Social introduction and } \\
\text { problem orientation } \\
\text { phase }\end{array}$} & \multicolumn{2}{|c|}{ Nature of task-related behavior } & Economides, 2008; Cox et al., 1991; Chan \\
\hline & Task oriented & Relationship oriented & \& Watkins, 1994; Oetzel, 1999; Phuong- \\
\hline & Individualists tend to exhibit more task- & Collectivists tend to focus more on & Mai et al., 2005, 2006; Shi et al., 2013; \\
\hline & oriented activities and focus on content- & aspects related to group norms and group & Tapanes et al., 2009; Weinberger et al., \\
\hline & \multicolumn{2}{|c|}{ Nature of conflict-related behavior } & 2007; Zhu, 2013 \\
\hline & Competitive behavior & Cooperative behavior & \\
\hline & $\begin{array}{l}\text { Individualists are more likely to exhibit } \\
\text { competitive behavior focused on } \\
\text { personal achievement. }\end{array}$ & $\begin{array}{l}\text { Collectivists are more likely to avoid } \\
\text { conflicts and demonstrate predominantly } \\
\text { cooperative behavior. }\end{array}$ & \\
\hline \multirow{9}{*}{$\begin{array}{l}\text { Collaborative problem- } \\
\text { solving phase }\end{array}$} & \multicolumn{2}{|c|}{ Nature of social and cognitive behavior } & Ouamani et al., 2014; Chang et al., 2002; \\
\hline & Open to disagreement & Preference for consensus & Gudykunst et al., 1996; Gunawardena \\
\hline & Individualists are more inclined to & Collectivists are more inclined to identify & et al., 2002; Hall, 1990; Oetzel et al., \\
\hline & identify and discuss conflicts in & and discuss points of consensus. They & 2000; Perera \& Wise, 2017; Phuong-Mai \\
\hline & knowledge and beliefs. They tend to have & tend to conform and try to be consistent & et al., 2005, 2006; Salili, 1996; Setlock \\
\hline & $\begin{array}{l}\text { more opinions independent of group } \\
\text { members. }\end{array}$ & with their collaborative partners. & $\begin{array}{l}\text { et al., 2004; Shi et al., 2013; Tapanes } \\
\text { et al., 2009; Vatrapu \& Suthers, } 2007 .\end{array}$ \\
\hline & \multicolumn{2}{|c|}{ Type of communication style } & \\
\hline & Direct & Indirect & \\
\hline & $\begin{array}{l}\text { Individualists tend to structure their } \\
\text { online contributions in an explicit, direct } \\
\text { manner with a focus on main points. } \\
\text { They also tend to be more literal. }\end{array}$ & $\begin{array}{l}\text { Collectivists tend to be indirect and } \\
\text { implicit. They place greater emphasis on } \\
\text { context and details than on main issues } \\
\text { and explicitness. }\end{array}$ & \\
\hline \multirow[t]{3}{*}{ Solution evaluation phase } & \multicolumn{2}{|c|}{ Nature of reason-giving } & Choi \& Nisbett, 2000; Nisbett \& \\
\hline & Analytical & Holistic & Norenzayan, 2002; Salas et al., 2004; \\
\hline & $\begin{array}{l}\text { Individualists tend to argue for a more } \\
\text { differentiated, analytic solution that also } \\
\text { seems most logically viable. }\end{array}$ & $\begin{array}{l}\text { Collectivists prefer a final solution that is } \\
\text { highly inclusive. }\end{array}$ & Vatrapu, 2008. \\
\hline
\end{tabular}


phases: problem orientation, problem solution, and solution evaluation (Ploetzner, Fehse, Kneser, \& Spada, 1999; Slof et al., 2010). These phases can be repeated and re-entered, i.e., students may go through the processes again or return to them if necessary. As shown in Table 1, building on previous research findings on intercultural differences and intercultural CSCL, first, specific discourse practices and interaction patterns were identified that are likely to emerge for students with an individualist orientation, on the one hand, and students with a collectivist orientation, on the other hand, and next, these practices and patterns were linked to the three phases of collaborative problem solving. For example, in the problem orientation phase, collaborating students are expected to orient themselves to the learning task, become aware of each other's background and establish a shared understanding of the problem. Previous studies have reported that students coming from collectivist cultures are more likely to stress the interpersonal relations between members of the group and cooperative actions aimed at collective goals (Cox et al., 1991; Phuong-Mai, Terlouw, \& Pilot, 2006) while students from individualist cultures stress mostly task-related activities and personal goals (Chen \& Starosta, 1998; Oetzel, 2001; Triandis, 1994). In more recent research, Vatrapu and Suthers (2007) claimed that students from individualist cultures are likely to see the collaborative learning environment as a medium to jointly identify problems and discuss conflicts in knowledge beliefs. Students from collectivist cultures, in contrast, are more likely to view the collaborative learning environment as a place to share information and explanations (Economides, 2008; Oetzel, Ting-Toomey, Yokochi, Masumoto, \& Takai, 2000; Vatrapu \& Suthers, 2007). Similarly, in the problem solution phase, students usually elaborate their points of view, discuss their points of view, reflect, and explain different discourse topics related to a learning task in question. However, students' I-C cultural orientation can affect the flow of discourse and transactivity of talk, which can in turn determine the extent of student involvement in the collaborative learning process and degree to which students refer to each other and build upon each other's contributions during this process (Weinberger et al., 2007). In the solution evaluation phase, students strive to find the most viable problem solution by gauging all options based on a specific evaluation system or on criteria (e.g., making calculations). Cultural differences in reasoning may then, in turn, influence how the members of a group reach decisions and draw conclusions during collaborative learning activities (Nisbett \& Norenzayan, 2002; Nisbett, Peng, Choi, \& Norenzayan, 2001). This view is supported by Nisbett, (2003) who argued that Westerners reasoned in an analytic and deductive way, whereas East-Asians were intuitive, holistic, and tolerated contradictions. Unlike Nisbett (2003), Lee and Johnson-Laird (2006) argued that there were no differences in reasoning between Chinese speakers in Hong Kong and Western students in Princeton. In view of all available evidence so far, however, one may suppose that "cultural differences in reasoning do exist, they seem to be in strategy rather than in underlying mechanisms of reasoning" (Johnson-Laird, 2013, p. 136).

Hofstede's framework has been challenged by a number of researchers. The critiques are mainly related to Hofstede's original research database/sample and generalizations regarding national cultures (for a review of these critiques, see Ess \& Sudweeks, 2005; McSweeney, 2002; Voronov \& Singer, 2002). The differentiation of cultures in terms of relative individualism and collectivism provides only initial insight into possibly critical cultural factors for working in a collaborative learning context and thus a small piece of the larger picture of multicultural collaboration. In some relevant studies, for instance, the personal characteristics of the collaborators have been found to prevail over cultural characteristics in terms of influencing the efficiency of the intercultural collaboration (Ting-Toomey, Oetzel, \& Yee-jung, 2001). However, cultural differences cannot always be reduced to individual differences (see $\mathrm{Na}$ et al., 2010, for a review). For this reason, the influence of collectivist and individualist cultural orientations on group work and collaboration processes has traditionally been studied at both the national and individual levels. Despite the critiques, Hofstede's framework still is the dominant approach to classify and compare national cultures.

\subsection{Collaboration scripts as means to foster CSCL}

The main purpose of CSCL is to promote online collaboration between students and thereby improve their learning and facilitate group cognition (Kreijns, Kirschner, \& Jochems, 2003; Stahl, 2010). This kind of learning is characterized by the negotiation of meaning and thus the sharing and construction of knowledge among students working together with the help of technology. Although CSCL offers great opportunities (e.g., development of collaboration skills and cognitive strategies; see Lehtinen, Hakkarainen, Lipponen, Rahikainen, \& Muukkonen, 1999 for review), its potential is difficult to realize because an online environment alone does not solve many of the challenges of collaborative learning (Lipponen, 2002). For this reason, a collaboration process is often structured and the collaborating students are given additional guidance (Van Bruggen, Boshuizen, \& Kirschner, 2003).

There is a well-documented body of CSCL research that reports the effectiveness of using collaboration scripts to stimulate/ support online collaboration (for overviews, see Fischer et al. (2013) and Kollar, Fischer, and Hesse (2006)). The use of collaboration scripts in a CSCL context can be viewed as providing scaffolding and thus guidance to students with regard to the learning task, the roles that must be played, and the sequence in which particular activities should be undertaken (Carmien et al., 2007). By following script instructions, specific interaction beneficial for the collaborative task performance can be initiated (Kolodner, 2007). The collaborative script may be presented via teacher instructions (e.g., oral presentation, handout materials) or the learning environment itself (e.g., online text, cues, prompts, graphic representations).

When Rummel and Spada (2005) integrated empirical findings regarding effective communication and computer-mediated collaboration, they were able to introduce an approach that subsumed the processes necessary for successful collaborative problemsolving. The initial, main, and final processes in this approach correspond to the three phases previously identified for collaborative problem-solving, namely: problem orientation, problem solution, and solution evaluation. Each of the three phases/processes includes a three-step cycle that entails (a) elicitation (i.e., individual work, which allows collaborative partners to bring in their own knowledge and ideas), (b) explication (i.e., discussion of individual ideas to ensure exchange of any unshared information), and (c) integration (i.e., combining of individual proposals to attain a joint solution). All of the phases and subcomponents require online 
collaborative behavior and are intended to structure the problem-solving process to make it efficient and effective (Slof et al., 2010).

Several empirical studies have proven that collaboration scripts can effectively support online collaboration among same-culture groups (e.g., Hämäläinen, Oksanen, \& Häkkinen, 2008; Rummel \& Spada, 2005; Schellens, Van Keer, De Wever, \& Valcke, 2007; Schoonenboom, 2008; Stegmann, Weinberger, \& Fischer, 2007). For example, Rummel and Spada (2005) examined the effects of a collaboration script on collaborative problem-solving processes and learning outcomes, compared to an unscripted control condition. Seventy-two students worked together in pairs. The collaboration script entailed specific scaffolds that instructed students to first provide input individually, second discuss the contributions, third revise their initial inputs based on the discussion, and finally build a consensus. Students collaborating with the script showed positive effects on process and outcome of the collaboration: They were able to provide joint solutions for the learning task of higher quality than students without the script. Comparable findings were found by Schoonenboom (2008) and Hämäläinen et al. (2008).

In addition to the need for a general collaboration script to guide the collaborative task performance, the results of studies concerned with intercultural differences between students in collaborative learning processes and online collaborative learning processes in particular suggest that additional guidance may be needed at times. There is existing empirical evidence in the CSCL literature stating that the same collaboration scripts may play out differently depending on cultural backgrounds of learners. For example, Popov et al. (2013) explored the effects of a collaboration script used by same- versus mixed-culture CSCL dyads in terms of their online collaborative behavior and quality of the online discussions. The findings showed that the introduced script did not help the students working in culturally mixed dyads to the same extent to engage in a qualitatively productive discussion when compared to same-culture dyads. One of the conclusions was that the design of a collaboration script to be used by culturally mixed groups of learners should incorporate additional culture-specific elements.

In a similar vein, Weinberger and his colleagues (see Weinberger et al., 2013) have conducted a study in which they examined the differential effects of a peer-critique collaboration script on inducing socio-cognitive conflicts in Finnish and German CSCL student groups. The German students showed more (constructive) conflict-oriented behavior in their online discussions than the Finnish students. That is, collaborative online patterns of behavior can vary even between seemingly closely related cultures in terms of the I$\mathrm{C}$ dimension. It has, moreover, been suggested that the bigger the cultural gap between learners in a group, the greater the probability of miscommunication in general (Triandis, 1994) and in an online learning environment in particular (Reeder, Macfadyen, Roche, \& Chase, 2004). The findings of that last study showed that learning environments and collaboration scripts need to be designed and implemented taking cultural differences into account. The researchers in that study further linked, on the basis of Hofstede (1991), the observed conflict resolution styles (i.e., domination, integration, or conflict avoidance) to the preponderance of the cultural dimensions of masculinity or femininity. Classifying cultures in terms of their masculine and feminine characteristics and identifying those elements that are needed for an Interculturally-Enriched Collaboration Script (IECS) to be tailored to the masculine and feminine cultural predispositions of students working in a group is a promising approach in this type of research. Based on the argumentation provided in Section 2.2, however, in the present study, an IECS was supplemented with critical intercultural elements based on the I-C dimension tailored to the individualist or collectivist cultural orientations of the students working collaboratively in a CSCL environment.

\subsection{Research questions}

The present study aimed to provide answers to the following three research questions:

1. Does the effect of an interculturally-enriched collaboration script (IECS) for culturally heterogeneous groups of students working in a CSCL environment on the students' attitudes towards online collaboration differ from that of a general collaboration script (CS)?

2. Does the effect of an interculturally-enriched collaboration script (IECS) for culturally heterogeneous groups of students working in a CSCL environment on the students' online collaborative learning behavior differ from that of a general collaboration script (CS)?

3. Does the effect of an interculturally-enriched collaboration script (IECS) for culturally heterogeneous groups of students working in a CSCL environment on the students' learning performance differ from that of a general collaboration script (CS)?

\section{Method}

\subsection{Participants}

First year students enrolled in an Environmental Sciences MSc program at a university in the Netherlands participated in this study. The total sample of 74 included 18 Dutch students and 56 international students; $53 \%$ of the students were female. The age of the participants ranged from 19 to 37 years, with a mean of 24 years (SD $=3.2$ ); $96 \%$ of the participants were under the age of 30 .

Of the international students, 18 came from Europe, 6 from Africa, 25 from Asia, 5 from South America, 1 from Central America and 1 from North America. The total number of countries represented in the study was 22 . And $98 \%$ of the international students had only arrived in the Netherlands two or three weeks prior to the implementation of this study. All of the participants had demonstrated English language proficiency when enrolling at the university where this research was conducted.

\subsection{Research design}

A randomized, two group, pretest-posttest research design was used to assess the effects of an IECS versus a general CS for 


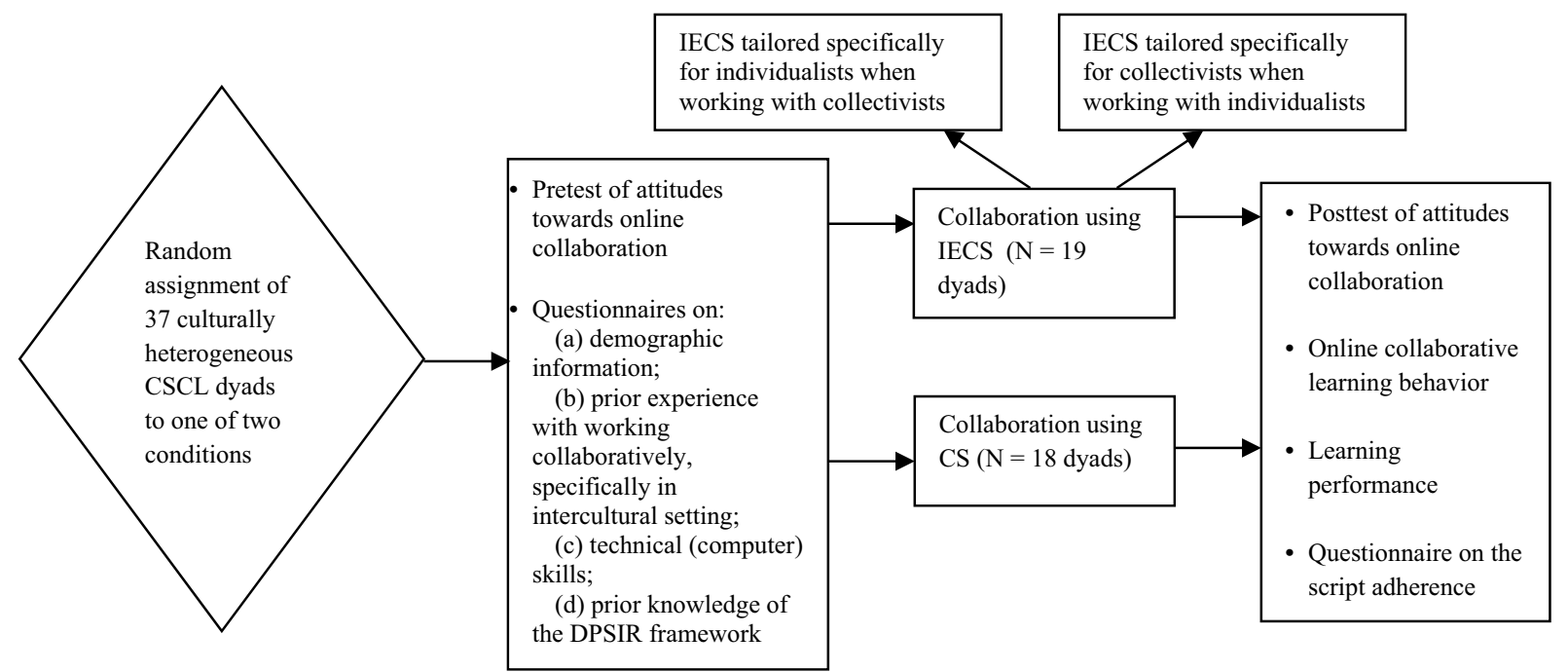

Fig. 1. Outline of research design.

IECS = intercultural enriched collaboration script.

$\mathrm{CS}=$ general collaboration script.

culturally heterogeneous groups of students working in a CSCL environment (see Fig. 1). The participants were randomly assigned to one of two conditions (i.e., IECS or CS), but it was further ensured that each dyad was composed of one student from a country with an individualist cultural orientation and one from a country with a collectivist cultural orientation. The students in each of the dyads did not know each other beforehand.

The cultural backgrounds of the students were determined by asking them to indicate their country of origin during the introductory session. The countries of origin were then coded using the individualist-collectivist dimension of Hofstede's individualism (IDV) index (see Hofstede et al., 2010). The ratings were standardized and set into a range from 0 (most collectivist) to 100 (most individualist); the world average IDV index is 43 (Hofstede, 2001).

We followed previous research (e.g., Gouveia, Clemente, \& Espinosa, 2003; Murray-Johnson et al., 2001) in dichotomizing the IDV index. As in these previous studies, we ranked all students in our sample by IDV index scale score and labelled the bottom half as collectivists (scores less than or equal to 48) and the top half as individualists (scores higher than or equal to 58) (see Table 2 for a list of dyad cultural compositions, countries of the participants and their associated Hofstede's IDV indices).

\subsection{Research setting, assignment, and study procedure}

As part of an introductory course Principles of Environmental Sciences for MSc students, the students had to analyze the problem of biodiversity collapse in tropical forests using a paper written by Laurance et al. (2012). The dyads collaborated online using the groupware program from the Virtual Collaborative Research Institute (VCRI; Jaspers, Broeken, \& Erkens, 2004) as the CSCL platform

Table 2

Dyad cultural compositions, IDV indices and number of dyads.

\begin{tabular}{lll}
\hline Dyad cultural compositions $^{\mathrm{a}}$ & Countries and IDV indices in brackets & Number of dyads \\
\hline D, Af & Netherlands (80) and Ghana (15), Tanzania (25) & 4 \\
D, As & Netherlands (80) and Thailand (20), China (20), Bangladesh (20), Uzbekistan ${ }^{\mathrm{b}}$ (22) & 12 \\
D, SA & Netherlands (80) and Brazil (2) & 1 \\
D, CA & Netherlands (80) and Honduras (2) & 1 \\
E, As & Germany (67), Belgium (75), France (71), Italy (76), Czech Republic (58) and India (48), China (20), Iran & 13 \\
& (41), Kazakhstan (14) & 1 \\
E, SA & Czech Republic (58) and Columbia (13) & 1 \\
E, Af & Belgium (75) and Ethiopia (20) & 3 \\
E, E & Germany (67), Italy (76) and Greece (35) & 1 \\
NA, Af & US (91) and Eritrea (27) & \\
\hline
\end{tabular}

${ }^{a}$ D(utch), E(urope - excluding the Netherlands), Af(rica), As(ia), SA(South America), CA(Central America), and NA(North America).

b Individualism values for countries in sample, using Hofstede's individualism (IDV) index (Hofstede et al., 2010; http://www.geert-hofstede. com/, downloaded September 8th 2012). Since Hofstede (Hofstede, 1991; Hofstede et al., 2010) did not investigate Uzbekistan and Kazakhstan in his studies, scores for IDV indices here were used from a study conducted by Safarov (2010) for Uzbekistan (i.e., the IDV index is 22) and a study conducted by Nezhina and Ibrayeva (2008) for Kazakhstan (i.e., the IDV index is 14). 
Table 3

Outline of study procedure.

\begin{tabular}{|c|c|c|c|}
\hline Day & Phases & Task number and name & Time (min) \\
\hline \multirow[t]{2}{*}{ Day 1} & \multirow{6}{*}{$\begin{array}{l}\text { Social introduction and problem orientation } \\
\text { phase }\end{array}$} & Explanation of the assignment and VCRI platform, introduction of the DPSIR model & 60 \\
\hline & & Completion of series of pretest questionnaires & 40 \\
\hline \multirow[t]{5}{*}{ Day 2} & & 1.1 (a) Task introduction (BBC documentary and article) & 120 \\
\hline & & Break & 30 \\
\hline & & 1.2 (b) Creation of personal profile & 15 \\
\hline & & 1.3 (c) Establishment of dyad & 15 \\
\hline & \multirow[t]{7}{*}{ Collaborative problem-solving phase } & 2.1 (a) Individual work on questions related to the learning task & 45 \\
\hline \multirow[t]{12}{*}{ Day 3} & & 2.2 (b) Exchange and discussion of individual ideas & 30 \\
\hline & & 2.3 (c) Completion of DPSIR model & 30 \\
\hline & & Break & 15 \\
\hline & & 3.1 (a) Individual work on possible solutions & 15 \\
\hline & & 3.2 (b) Exchange and discussion of preferred solutions and support for them & 30 \\
\hline & & 3.3 (c) Integration of individual proposals and creation of list of possible solutions & 20 \\
\hline & \multirow[t]{6}{*}{ Solution evaluation phase } & Break & 15 \\
\hline & & 4.1 (a) Individual prioritization of the responses & 30 \\
\hline & & $\begin{array}{l}4.2 \text { (b) Exchange of the individual prioritization of the responses and its supporting } \\
\text { argumentation }\end{array}$ & 30 \\
\hline & & 4.3 (c) Integration and reporting of the overall prioritization of the responses & 15 \\
\hline & & Completion of posttest questionnaire and debriefing & 40 \\
\hline & & & 595 \\
\hline
\end{tabular}

(see below for further description of the platform). When doing this, the students were expected to: (1) analyze the problem of biodiversity loss in terms of causes and effects, (2) propose possible solutions to avert biodiversity loss, and (3) select the most viable solutions for the problem of biodiversity loss. The students were expected to complete a Driver-Pressure-State-Impact-Response (DPSIR) model for the environmental problem under study (Fortuin, van Koppen, \& Leemans, 2011). The students had to complete this online collaboration assignment to pass the course.

A pilot study had been conducted with 5 culturally diverse dyads (i.e., 10 students who did not participate in the present study) to check on the appropriateness of the script instructions, applicability of the research instruments, adequacy of task difficulty, and technical functioning of the learning platform.

In the actual experiment, a single plenary (i.e., introductory) session and two online working sessions were held on three consecutive days (see Table 3 for further details on the collaborative learning process and timetable for the experiment). The total time required for completion of the CSCL assignment was about $10 \mathrm{~h}$; this included completion of pretest/posttest questionnaires and three breaks. For the online sessions, the students were seated at individual computers. All students were placed to work in four computer rooms and students collaborating in one dyad were not physically co-present. All students were interacting with the study personnel and with each other in English.

After the introduction of the assignment, the VCRI groupware program, and the procedures for collaboration on the first day, the participants were asked to complete the pretest questionnaires. This provided background demographic information, information for the outcome measures, and information for control (see also Fig. 1).

On the second day, the students were given time to individually read the Laurance et al. (2012) paper on "Averting biodiversity collapse in tropical forest protected areas" and collectively watch the BBC Planet Earth documentary on biodiversity. Social introduction of the dyads then occurred, and the problem orientation phase of the CSCL procedure was undertaken (i.e., steps 1.2.-2.1 in Table 3).

On the third day, the collaborative problem-solving and solution evaluation phases were conducted. This involved three subtasks per phase (i.e., steps 2.2-4.3 in Table 3). Each student then completed the posttest questionnaire concerned with their attitudes towards online collaboration, and information for control (see also Fig. 1).

\subsection{CSCL platform}

The VCRI groupware program has a number of features that have been specifically designed to facilitate collaborative online activity (see Fig. 2 for a screenshot). These include: (1) a Chat tool to allow students to communicate with their collaborative partner via instant messages; (2) a Source tool for instructions on how to proceed with a task and the supply of the background information needed to complete a particular task (e.g., assignment description, literature); (3) a Cowriter tool, which is a shared word processor that allows students to simultaneously work on a text; (4) a Diagrammer tool to collaboratively create representations of various sorts (e.g., diagrams, flow charts); and (5) a Notes tool, which is a personal space that can be used to write down some remarks. The CS and the IECS scripts used in this study were embedded in the Source tool.

\subsection{Use of the collaboration scripts within the CSCL environment}

All of the students in the two conditions were expected to work through the same collaborative learning steps (see Table 2). The 


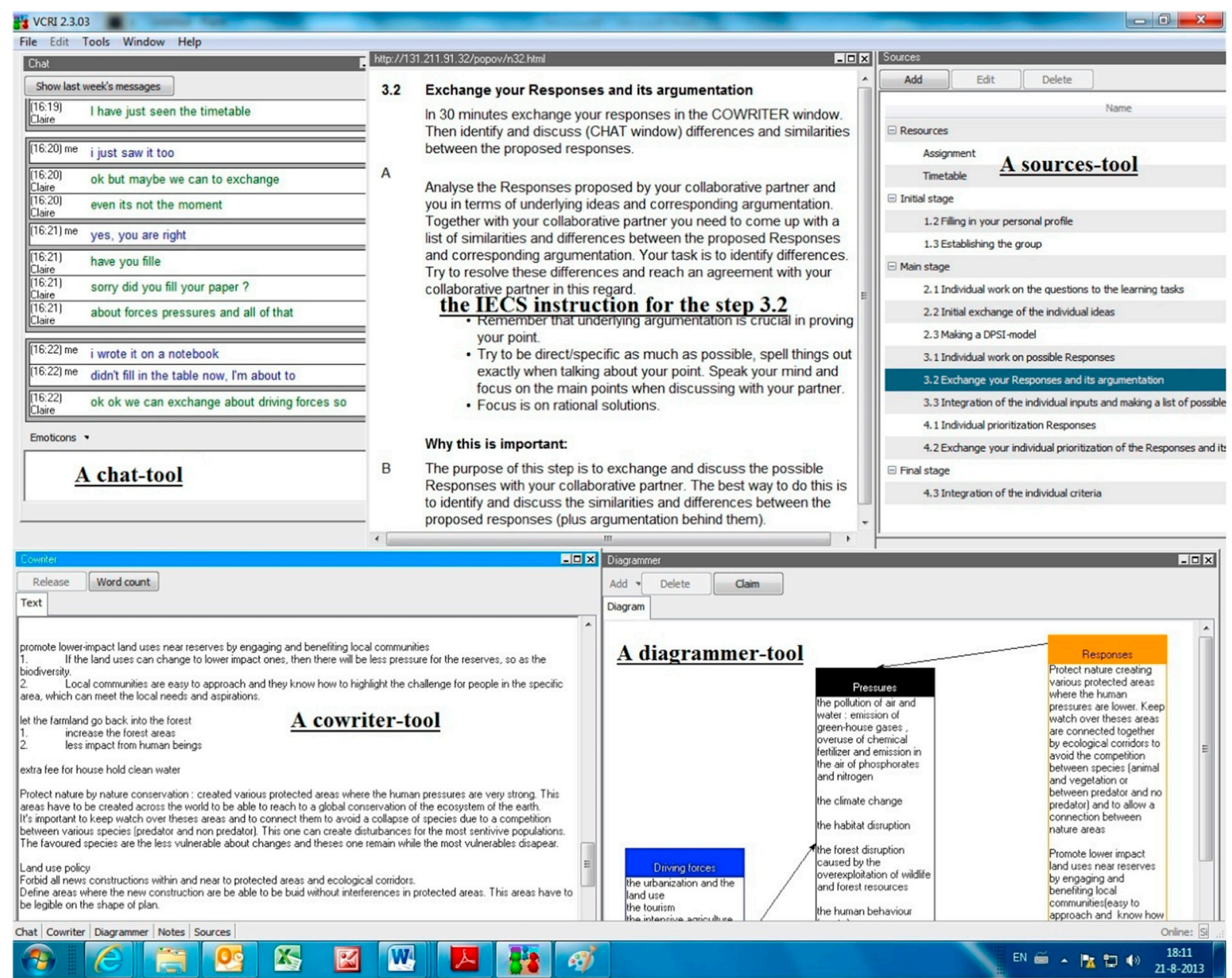

Fig. 2. Screenshot of the VCRI platform.

only difference was that the general CS only provided scaffolding WHAT to do during each step. The IECS, in contrast, provided three types of scaffolding for each collaborative learning step: (1) general instructions on WHAT to do, which is the same as in the CS; (2) instructions on HOW to proceed with a particular subtask; and (3) an explanation of WHY that particular subtask is important. IECS scaffolds HOW and WHY to do a particular learning step were made different to each student in a dyad. Specifically, instructions were tailored to students with an individualist orientation, on the one hand, and students with a collectivist orientation, on the other hand, on how to approach their collaborative partner and how to engage in a collaborative discourse.

In this study, both the CS and IECS involved text scaffolds represented within the CSCL platform. The introduction to the task at the plenary introductory session stressed the importance of following the script instructions and each student was monitored to see that the instructions were indeed followed. At the end of the experiment, the script adherence was checked in two ways: (1) by asking the students immediately following completion of the experiment if they had indeed followed the instructions and, if yes, how frequently; (2) by collecting interaction log files. For the latter, a link entitled "WHY the subtask is important" was created, which meant that the students had to click on the link to access the particular rationale (see Fig. 3). This allowed us to indirectly measure the use of the WHY information by calculating the number of hits for this link. In the IECS condition, the students clicked on the "WHY the subtask is important" link on average four times during the collaboration process. This was consistent with what they reported when asked after the study. In the CS condition, all of the students reported that they had tried to follow the "WHAT to do" instructions as much as possible.

The main purpose of the "WHAT to do" script scaffolds for the collaboration steps was to help coordinate the corresponding learning activities. Step-by-step guidelines and timelines were provided for the subtasks constituting the collaborative problemsolving process. For instance, "in 30 min make a conceptual DPSI model in the Diagrammer window, together with your collaborative partner, indicating Driving forces, Pressures, States, and Impacts related to the collapse of biodiversity." These instructions were then followed by those for the next subtask. For instance, "in $15 \mathrm{~min}$, make use of the designed DPSI model to identify three possible Responses. Write individually your three responses in the Notes window and provide supporting argumentation for these responses." IECS scaffolds HOW and WHY to do a particular learning step were intended to evoke specific interactions between the culturally 


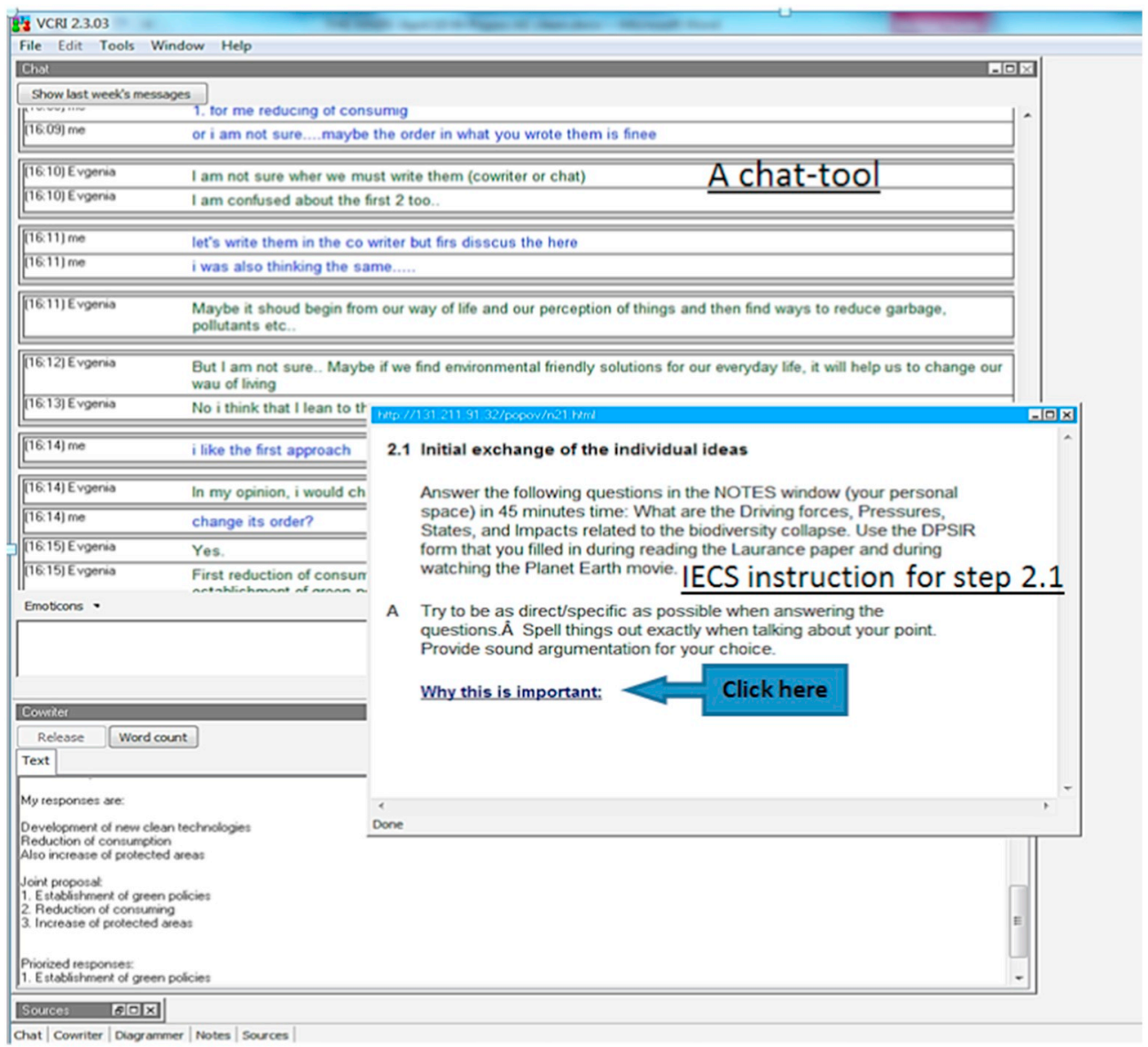

Fig. 3. Screenshot of step 2.1 - IECS scaffolding within a VCRI environment.

heterogeneous students, increase the frequency of specific behaviors, and thereby facilitate the collaborative problem-solving task. Building on previous research findings on intercultural differences (see Table 1), we identified specific discourse practices and interaction patterns that were likely to emerge in culturally heterogeneous CSCL groups and tailored the instructions to students with an individualist orientation, on the one hand, and students with a collectivist orientation, on the other hand. The tailored instructions on how to approach a collaborative partner and engage in a collaborative discourse were expected to enhance mutual understanding, engagement in debate, and convergence on the steps to be taken to complete the collaborative learning activities. In the following paragraphs, the sequence of activities that the students had to follow is specified and, in Table 4, examples of the culturally-specific instructions provided for the various activities are given.

\subsubsection{Social introduction and problem orientation phase}

In the initial phase of the collaboration process (Table 3, steps 1.2-2.1), the students were asked to create personal profiles, exchange and discuss them in the dyads. As opposed to the CS script, the IECS instructions for doing this included questions that addressed both the content- and task-related experiences but also the personal backgrounds of the students in the dyad. Specifically, both of the students in the dyad were instructed with the help of the IECS to construct a concrete idea of themselves and their collaborative partners based on the knowledge and experiences shared with regard to the content of the assignment. In addition, the students were instructed to introduce themselves to their partner and get to know their partner in terms of their partner's personal background. It was expected that the receipt of specific information about the collaborative partner in each dyad would help the students build a good working relationship at the start of their collaboration and solve the assigned task together.

In addition, it was explicitly stated in the introductory instructions for all of the students in the two conditions that the assigned task was aimed at collaborative learning with no teacher control and that the task concerned an open-ended problem with no single correct solution. It was also explicitly stated in the introductory instructions that the argumentation used by the students to support their proposed solution(s) was crucial. The collaborating students were further asked to be open with each other and to consider the learning platform a safe environment for the exchange of ideas to jointly solve the assigned problem. 


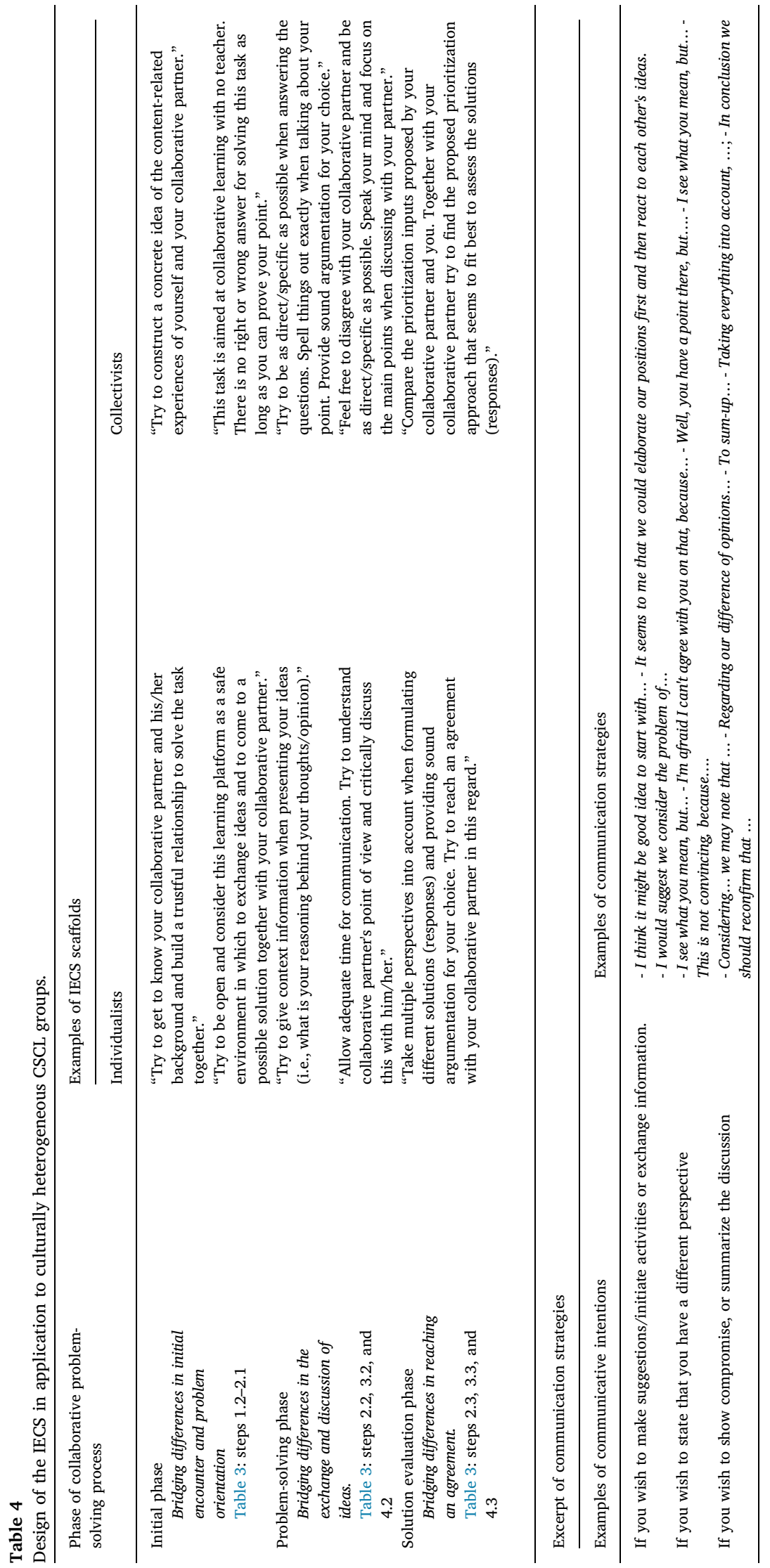




\subsubsection{Collaborative problem-solving phase}

In the main phase of the collaboration process (Table 3 , steps $2.2,3.2$, and 4.2 ), the students were instructed to exchange and discuss their individual ideas.

Students with a collectivist orientation were instructed via the IECS (but not in the CS condition) to feel free to disagree with their partner and to be as direct and specific as possible (e.g., "Feel free to disagree with your collaborative partner. There is no right or wrong answer for solving this task as long as you can prove your point. Support your points of view by providing some examples or reference to literature."). The students with an individualist orientation were instructed via the IECS to share as much information and ideas concerned with how to solve the task as possible with their fellow student. It was explained that the best way to do this is to ask their partner to share their ideas about how to solve the task (e.g., "Allow adequate time for communication. This means make time to fully understand your partner's answers to the questions and give your collaborative partner time to think of a way to respond. Try to share, as much as you can, with your fellow student about ideas that you can think of on how to solve the task.").

Both students in the dyad were instructed to see this online communication as a means to exchange information, ideas, and opinions but also "engage" with their collaborative partner (e.g., "Try to see this online communication both as a way of exchanging information, ideas/opinions and as a form of discussing them with your collaborative partner. Try to share, as much as you can, with your fellow student about information/ideas that you can think of on how to solve the task".). It was expected that these IECS scaffolds would foster collaboration and debate.

The cultural communicative style of the participants was also expected to affect the extent to which they would present information, reflect upon this, and elaborate upon it. The students with an individualist orientation were therefore instructed to give contextual information when communicating with their partner (e.g., "Try to give context information when preparing your ideas, explain your underlying reasoning behind your ideas."). The students with a collectivist orientation were instructed to be as direct and specific as possible; to spell things out precisely when talking about their points; and to provide information to support their points of view (e.g., "Try to be direct/specific as much as possible, spell things out exactly when talking about your point. Speak your mind and focus on the main points when discussing with your partner.").

It was expected that these IECS scaffolds would stimulate the communication flow and mutual understanding within the dyads.

\subsubsection{Solution evaluation phase}

During the last phase of the collaborative process (Table 3, steps 2.3, 3.3, and 4.3), the students were instructed to summarize and synthesize their contributions to come up with a joint solution for the problem.

The students with an individualist orientation were instructed to be as open as possible while working on the solution to the problem and to consider a number of alternatives (e.g., "It is possible that there is no concrete answer to this task, be open to see the approaches to the learning task in very diverse ways."). Students with a collectivist orientation were instructed to be as specific as possible while integrating ideas to come up with a joint solution to the problem (e.g., "Try to be logical while formulating your joint proposal with possible responses to the problem of biodiversity loss. Focus on solutions that seem logical and viable for this particular problem.").

Both students in the dyad were further instructed that, even though they may have opinions that differ from each other, overall assignment success depends on how well they resolve these differences and reach agreement on a solution to the problem.

In addition, a list of communication strategies to be used in all phases of the collaboration process was provided on paper as part of the IECS but not the CS (see Table 4 for an excerpt of communication strategies). The list of communication strategies included interaction prompts and sentence openers. The strategies were based upon the interaction analysis model developed by Gunawardena, Lowe, and Anderson (1997), and they followed the rules of net etiquette as recommended by Shapiro and Anderson (1985). Students were encouraged to call upon the communication strategies whenever they had problems getting their message across.

\subsection{Measures}

\subsubsection{Pretest and posttest measures of attitudes towards online collaboration}

A 17-item questionnaire (Thompson \& Ku, 2006) was used to measure the students' attitudes towards online collaboration both before and after the experiment. The original questionnaire consisted of 18 items but one item was not relevant for the present study and therefore removed (i.e., "I found our group discussion of team agreements at the beginning of the semester helpful."). The students were asked to indicate the extent to which they agreed or disagreed with the statements $(1=$ Strongly Disagree; 5 = Strongly Agree; higher scores thus reflect a more positive attitude towards online collaboration). Some sample questionnaire items are: "I feel comfortable providing feedback to my peers," "I like to share information and ideas with other learners," or "I enjoy using the computer to communicate with my classmates online." The Cronbach's alpha coefficients for the reliability of the questionnaire were sufficiently high: 0.86 at pre-test and 0.82 at post-test.

Attitudes towards online collaboration were analyzed at the level of the dyad. To transform the individual attitude scores to dyad scores, we subtracted the individual attitude score at pretest from the individual attitude score at posttest for each of the two students in a dyad and then calculated the mean of the individual attitude change scores (i.e., added the scores for attitude change together for the two students in the dyad and then divided by 2 or, in other words, the number of students in the dyad). This produced a mean attitude change towards online collaboration per dyad. 
Table 5

Collaborative behavior coding scheme of Curtis and Lawson (2001) with examples obtained from chat protocols in present study.

\begin{tabular}{|c|c|c|}
\hline $\begin{array}{l}\text { Main collaborative behavior } \\
\text { categories }\end{array}$ & Subcategories & Examples obtained from chat protocols \\
\hline Planning & $\begin{array}{l}\text { Group skills: a generic code applied to expressions that } \\
\text { encourage group activity and cohesiveness. } \\
\text { Organizing work: planning group work; setting shared } \\
\text { tasks and deadlines } \\
\text { Initiating activities: setting up activities such as chat } \\
\text { sessions to discuss the progress and organization of } \\
\text { group work. }\end{array}$ & $\begin{array}{l}\text { - Take your time. I have a great view over here. If there is anything } \\
\text { you don't understand, feel free to ask. } \\
\text { - Let's start writing now so that we can exchange later... - Do we leave } \\
\text { now and pick up from where we stopped tomorrow? } \\
\text { - Let's start with the driving forces. Shall we begin with exchanging } \\
\text { our ideas? }\end{array}$ \\
\hline Contributing & $\begin{array}{l}\text { Help giving: responding to questions and requests from } \\
\text { others } \\
\text { Feedback giving: providing feedback on proposals from } \\
\text { others } \\
\text { Exchanging resources and information to assist other } \\
\text { group members } \\
\text { Sharing knowledge: sharing existing knowledge and } \\
\text { information with others } \\
\text { Challenging others: challenging the contributions of } \\
\text { other members and seeking to engage in debate } \\
\text { Explaining or elaborating: supporting one's own position } \\
\text { (possibly following a challenge) }\end{array}$ & $\begin{array}{l}\text { - Because the items show up off screen if you don't have it maximized. } \\
\text { - It sounds like we have the same driving forces except you added } \\
\text { change in rainfall patterns. - Well, you have a point there. } \\
\text { - I'm sending you an example I read about today. } \\
\text {-Alright, I added your responses from yesterday and added two more. } \\
\text { - If we draw it directly from the movie, "combination of number of } \\
\text { people and consumer needs has led to a growth in economy and how } \\
\text { we use our wealth." } \\
\text { - I'm sorry to be so bold, but I think my way is better since it takes the } \\
\text { effects for society into account. If you can prove otherwise or have a } \\
\text { better solution, I would be happy to hear that } \\
\text { - I think I would go with sustainable population because of the less } \\
\text { energy consumption, plus land protection and damming of rivers }\end{array}$ \\
\hline Seeking input & $\begin{array}{l}\text { Help seeking: request for assistance from others } \\
\text { Feedback seeking: seeking feedback to a position } \\
\text { advanced } \\
\text { Advocating efforts: urging others to contribute to the } \\
\text { group effort }\end{array}$ & $\begin{array}{l}\text { - Could you tell me how to add the arrows? } \\
\text { - The second, then, should be population controls; the third, a green } \\
\text { economy. Do you agree with me? What's your opinion? } \\
\text { - Okay, should we continue then? } \\
\text { - Are you ready to write? - Are you working on it now, because I need } \\
\text { your input to continue. }\end{array}$ \\
\hline Reflection/monitoring & $\begin{array}{l}\text { Monitoring group effort: comments about the group's } \\
\text { processes and achievements } \\
\text { Reflecting on medium: comments about the effectiveness } \\
\text { of the medium for supporting group activities }\end{array}$ & $\begin{array}{l}\text { - We're almost done, yeah! So excited. - So looks like we only need to } \\
\text { do the final stage. - Can you change it or is the program not working? } \\
\text { - I was trying to figure out how to make arrows in the diagram } \\
\text { section, but it's not working. }\end{array}$ \\
\hline Social interaction & $\begin{array}{l}\text { Social interaction: conversation about social matters } \\
\text { that are unrelated to group task. This activity helps to } \\
\text { 'break the ice'. }\end{array}$ & $\begin{array}{l}\text { - How is the day going so far? } \\
\text { - I missed another class because of a flat tire...but I managed to join } \\
\text { the lab session. }\end{array}$ \\
\hline
\end{tabular}

\subsubsection{Measuring online collaborative learning behavior}

Chat protocols were analyzed to determine the extent to which the IECS and CS affected the students' online collaborative behavior. We drew upon the coding scheme of Curtis and Lawson (2001) to identify relevant behavioral categories for working in an online collaborative environment. In many studies of computer-mediated collaboration and cross-cultural collaboration, the coding scheme of Curtis and Lawson was used to analyze the behavior of students engaged in collaborative learning (for details, see e.g., Curtis and Lawson (2001), Kim and Bonk (2002) or Swigger, Hoyt, Serçe, Victor, and Alpaslan (2012)). Five main categories of online collaborative behaviors were identified: planning, contributing, seeking input, reflection/monitoring of medium, and social interaction. Each category of collaborative behavior had several subcategories, which are illustrated in Table 5. In total, there are fifteen subcategories of collaborative behavior.

Pilot testing of the coding scheme showed its suitability for analyzing the data obtained in our study. Every posted utterance that indicated a specific collaborative behavior was regarded as a coding unit. The utterances contained mostly phrases and sentences. Salutatory and closing utterances were ignored. Both inter-rater agreement between two trained coders (Cohen's $\mathrm{k}=0.83$ ) (Landis $\&$ Koch, 1977) and intra-coder test-retest reliability for each coder for $10 \%$ of the data (95\% of identical scores) were sufficiently high.

\subsubsection{Measuring learning performance}

To assess the quality of the group work on the assignment, quantitative criteria were developed by experts in the area of environmental sciences (see Table 6). The group output from the Diagrammer tool was analyzed to assess completion of the DPSI model and the group output from the Cowriter tool to assess the argumentation provided for the solutions presented by each dyad of students. In addition, content analyses were conducted to identify the use of task-related concepts in the Diagrammer tool, Cowriter tool, and Chat tool.

Assessment was done using a five-level rating scale for each of the four criteria (i.e., width, correctness, structure, and argumentation). Two expert coders, using the same assessment criteria, coded students' group work outputs independently. Both interrater agreement between two expert coders (Cohen's $\mathrm{k}=0.82$ ) (Landis \& Koch, 1977) and intra-coder test-retest reliability for each coder for $15 \%$ of the data ( $90 \%$ identical scores) were sufficiently high. Subsequently, the points assigned for each dyad of students were summed and then divided by 4 (i.e., total number of criteria) to obtain a mean quality score, which could range between 1 and 5 per dyad. 
Table 6

Quantitative criteria used to assess group learning performance.

\begin{tabular}{|c|c|}
\hline Assessment criteria (rated along a scale of 1 to 5 ) & Description of the criterion \\
\hline 1. Width ("very inadequate" to "very adequate") & $\begin{array}{l}\text { The degree of elaboration for the DPSI model (i.e. total number of DPSI items } \\
\text { included in the model). }\end{array}$ \\
\hline 2. Correctness ("very incorrect" to "very correct") & $\begin{array}{l}\text { The degree to which items in the DPSI model are included and positioned } \\
\text { correctly. If one item is not included or positioned incorrectly, the entire box is } \\
\text { considered wrong and } 1 \text { point is subtracted from the possible total of } 5 \text { points. }\end{array}$ \\
\hline 3. Structure ("not at all structured" to "very well structured") & $\begin{array}{l}\text { The degree to which the DPSI model is constructed and presented in an orderly } \\
\text { manner. }\end{array}$ \\
\hline $\begin{array}{l}\text { 4. Argumentation ("no explanation for the priorities" to "clearly and } \\
\text { correctly explain prioritization, with reference to a source"). }\end{array}$ & $\begin{array}{l}\text { The degree to which a particular student dyad supported and justified arguments } \\
\text { using examples, proofs, and reasonable evidence related to the prioritization of } \\
\text { the identified responses in the cowriter tool. }\end{array}$ \\
\hline 5. Use of task-related concepts & $\begin{array}{l}\text { The frequency of use for task-related concepts (i.e., environment, society, and } \\
\text { responses) in Diagrammer tool, Cowriter tool, and Chat tool. }\end{array}$ \\
\hline
\end{tabular}

The content analysis of the Diagrammer, Cowriter, and Chat tools was done in terms of the list of 243 task-related concepts composed by two experts in the field of environmental sciences. The list had three main categories and eight subcategories. The main category of Environment had two subcategories: Abiotic (e.g., air, $\mathrm{CO}_{2}$, soil) and Biotic (e.g., park, habitat, forest). The main category of Society had three subcategories: Stakeholders (e.g., consumer, farmer), Infrastructure (e.g., city, dams), and Societal Processes (e.g., awareness, behavior). Finally, the main category of Responses (i.e., possible solutions to the environmental problem) had three subcategories: Technological (e.g., irrigation, renewable), Policy (e.g., conservation, education), and Other (e.g., campaigns, research). The coding of the main categories and their corresponding subcategories was done using the Multiple Episode Protocol Analysis (MEPA) computer filter which applies 694 "if-then" decision rules and pattern matching to identify concepts (see for more details Erkens and Janssen (2008)). When compared to hand-coding of $10 \%$ of the data from the three tools, overall agreement of $74 \%$ and a Cohen's kappa of 0.71 were found.

\subsubsection{Control measures}

Prior to the start of the experiment, a questionnaire was administered to collect information on the participants' age, gender, country of origin, duration of stay in the Netherlands (for non-Dutch students), and prior knowledge of the DPSIR framework. The participants were also asked to rate their experiences with group work in the form of face-to-face interaction, online collaboration, and intercultural collaboration along a five-point scale ( 1 = "very little"; 5 = "very much"). Finally, the students were presented five multiple-choice questions to assess their level of computer skill (i.e., knowledge necessary to work with the CSCL system). The questions addressed the use of the World Wide Web browser, MS Word, MS Excel, and other Internet programs used for communication like Discussion boards, E-mail, and chat applications.

\subsection{Analyses}

Analyses of variance were conducted to compare the control measures for the two conditions. Chi-square tests were used to test whether the distribution of males and females within the two conditions was equivalent.

To answer our first research question and thereby compare the effect of the IECS and CS on students' attitudes towards online collaboration, a univariate ANOVA was undertaken with condition (IECS vs. CS) as the independent variable and aggregate mean of attitude change towards online collaboration as the dependent variable. Shapiro-Wilk test showed that the normality distribution of the error terms assumption was not violated $(\mathrm{W}=0.98, p=.72)$.

To answer our second research question and thereby compare the effect of the IECS and CS on the online collaborative learning behavior of the students, we used non-parametric tests, Wilcoxon Rank Sum tests (Hollander, Wolfe, \& Chicken, 2013), which sum the ranks of observations in each condition and compare their differences. The reason for not using one-way multivariate analyses of variance (MANOVA) as appropriate is that the normality distribution of the error terms assumption was violated for many of the behavior categories and subcategories.

The patterns of collaborative behavior displayed during the collaborative learning task were examined in a lag sequential analysis (Bakeman \& Quera, 1995; Wampold \& Margolin, 1982). This was done to (1) determine the significance of the behavioral transitions (i.e., when one collaborative behavior was likely to be followed by another) and (2) identify significant differences between the conditions in behavioral transitions. The MEPA software was used to analyze the coded behavior sequences (Erkens, 2005). Based on the obtained codes from the quantitative content analysis of the behavior categories, the coded strings were organized chronologically and a sequential analysis was conducted on the strings. The sequential analysis allowed to determine the frequency of each behavioral event in succession, and the significance of a behavioral sequence when one collaborative behavior followed another. Subsequently, in order to determine whether differences in the behavioral patterns between the IECS and CS conditions are statistically significant, effect sizes, as measured by transformed kappa $\left(\mathrm{k}^{\prime}\right)$, were examined to determine the direction and magnitude of any significant differences in the behavioral patterns for the IECS and CS conditions (Wampold \& Kim, 1989). Transformed kappa provides an index of effect size that can be used to compared conditions or groups (Wampold, 1992). The transformed kappa ranges 
from -1.00 to +1.00 , with zero indicating no sequential association between the subsequent collaborative behavior and the antecedent collaborative behavior. The transformed kappa can range from -1 (which "indicates that the number of transitions from $i$ to $j$ occurred to the minimum extent possible") to +1 (which "indicates that the number of transitions occurred to the maximum extent possible, given the base rates") (Wampold, 1995, p. 207). For each dyad, the transformed kappas were calculated for 47 transitions out of 225 possible transitions. A total of 47 transitions were analyzed on the basis of the criterion of at least 10 or higher percentage indication of the conditional probabilities of transitions in either the IECS or the CS condition. Univariate ANOVAs were then conducted to compare the transformed kappas for the 47 transitions in the two conditions (IECS vs. CS).

To answer our third research question and thereby compare the effect of the IECS and CS on student learning performance, a univariate ANOVA was undertaken with condition (IECS vs. CS) as the independent variable and aggregate mean quality of learning performance as the dependent variable. The Shapiro-Wilk test showed that the normality distribution of the error terms assumption was not violated $(\mathrm{W}=0.97, p=.98)$.

The individual was adopted as the unit of analysis to ensure an equal distribution of the students across the two conditions with regard to age, gender, prior knowledge, and so forth. Online collaborative behavior and student learning performance were measured and thus analyzed at the level of the dyad. That is, the individual learning behavior and learning performance scores clustered within dyads and could therefore not be analyzed independently (Kapur, 2008; Stahl, 2010).

\section{Results}

\subsection{Control measures}

None of the participants had prior knowledge of the DPSIR framework. No significant differences were found between the IECS and CS conditions with respect to age, $F(1,72)=0.30, p=.58$, the computer skills, $F(1,72)=0.16, p=.33$, or prior group work experience, $F(1,72)=1.25, p=.26$. The distributions of males and females were also similar in the two conditions (Chisquare $=0.205, d f=1, p=.65$ ). These results showed that the random assignment of students to the two conditions led to no significant differences in terms of students' prior knowledge, group work experiences, technical (computer) skills, age, and gender. On average, two-three weeks was length of stay in the Netherlands for non-Dutch students, first year MSc students. Table 2 indicated the country of origin of all student participants in the study.

\subsection{Attitudes towards online collaboration}

The change in attitudes towards online collaboration was significantly higher for the dyads in the IECS condition than the dyads in the CS condition (IECS $M=0.36, \mathrm{SD}=0.29$ versus CS $M=0.15, S D=0.26, F(1,35)=4.78, p<.05, d=0.76$ ). In other words, students' attitudes towards collaboration changed more in a positive direction in the IECS condition than in the CS condition.

\subsection{Online collaborative learning behavior}

\subsubsection{Behavioral categories}

For the frequency of utterances reflecting the Planning category of collaborative behavior (i.e., the subcategories Group, Organizing work, Initiating activity), Wilcoxon Rank Sum non-parametric test showed the dyads in the IECS condition to exhibit a statistically higher frequency of Initiating activities and statistically lower frequency of Organizing work than the dyads in the CS condition (see Table 7).

For the Contributing subcategories (i.e., Help giving, Feedback giving, Exchange resources, Sharing knowledge, Challenging, and Explaining), the dyads in the IECS condition showed a statistically higher frequency of the Challenging subcategory and lower frequency of the Exchanging resources and Sharing knowledge subcategories than the dyads in the CS condition (see Table 7).

For the Social interaction category of collaborative behavior, which was composed of only off-task comments on social matters, the dyads in the IECS condition exhibited a statistically lower frequency of occurrence than the dyads in the CS condition.

There were no significant differences for the collaborative behavior categories of Seeking input and Reflection/Monitoring and their corresponding subcategories.

\subsubsection{Behavioral patterns}

The lag sequential analyses were conducted separately for 3066 and 3744 utterances in the IECS and CS conditions, respectively. The transitional probabilities for the 15 subcategories of collaborative behavior were calculated and those found to be significant incorporated into the behavioral transition diagrams presented for the IECS condition in Fig. 4 and the CS condition in Fig. 5.

Only positive z-scores are depicted in the diagrams. A z-score greater than 1.96 means that the transition between the two subcategories was statistically significant - it occurred significantly more often than might be expected by chance based on the frequency probability $(p<.05)$ (Bakeman \& Gottman, 1997; Wampold \& Margolin, 1982). These diagrams depict the flow of behavior in the online discussions; more likely interactions are indicated by thicker arrows and less likely interactions by thinner arrows. Each arrow points in the direction of the transition with the conditional probability of this happening presented as well. In Fig. 4, for example, Feedback seeking (FeedbSeek) is likely to be followed by Feedback giving (FeedbGiv) for 62.1\% of the occurrences of Feedback seeking on average. So-called self-transitions are indicated by semi-circular arrows and show, for example in Fig. 4, a Social interaction utterance to be followed by another Social interaction utterance from either one's partner or oneself in 
Table 7

Results of the Wilcoxon Rank Sum non-parametric tests for collaborative behavior categories and subcategories according to condition.

\begin{tabular}{|c|c|c|c|}
\hline \multirow[t]{2}{*}{ Collaborative behavior main categories and subcategories } & \multicolumn{2}{|c|}{ Rank sums of } & \multirow[t]{2}{*}{ Exact test $p$} \\
\hline & IECS & CS & \\
\hline Planning & 313.5 & 389.5 & 0.1520 \\
\hline Group & 356.5 & 346.5 & 0.9113 \\
\hline OrgWork & 262 & 441 & $0.0020^{* *}$ \\
\hline InitActiv & 459.5 & 243.5 & $0.0020^{* * *}$ \\
\hline Contributing & 380.5 & 322.5 & 0.5627 \\
\hline HelpGiv & 334 & 369 & 0.4190 \\
\hline FeedbGiv & 392 & 311 & 0.3540 \\
\hline ExchResour & 296 & 407 & $0.0161^{*}$ \\
\hline SharKnowl & 276.5 & 426.5 & 0.0089 ** \\
\hline Challenge & 361 & 342 & $0.0003^{* *}$ \\
\hline Explain & 407.5 & 295.5 & 0.1615 \\
\hline Seeking input & 320 & 383 & 0.2181 \\
\hline HelpSeek & 338.5 & 364.5 & 0.4993 \\
\hline FeedbSeek & 322.5 & 380.5 & 0.2480 \\
\hline AdvocatEffort & 323 & 380 & 0.2516 \\
\hline Reflection/monitoring & 311.5 & 391.5 & 0.1316 \\
\hline MonitGroupEffort & 306.5 & 396.5 & 0.0967 \\
\hline Reflecting on medium & 318.5 & 384.5 & 0.1935 \\
\hline Social interaction & 265.5 & 437.5 & $0.0030^{* *}$ \\
\hline
\end{tabular}

IECS = intercultural enriched collaboration script.

$\mathrm{CS}=$ general collaboration script.

* Significant at $p<.05$.

*** Significant at $p<.01$.

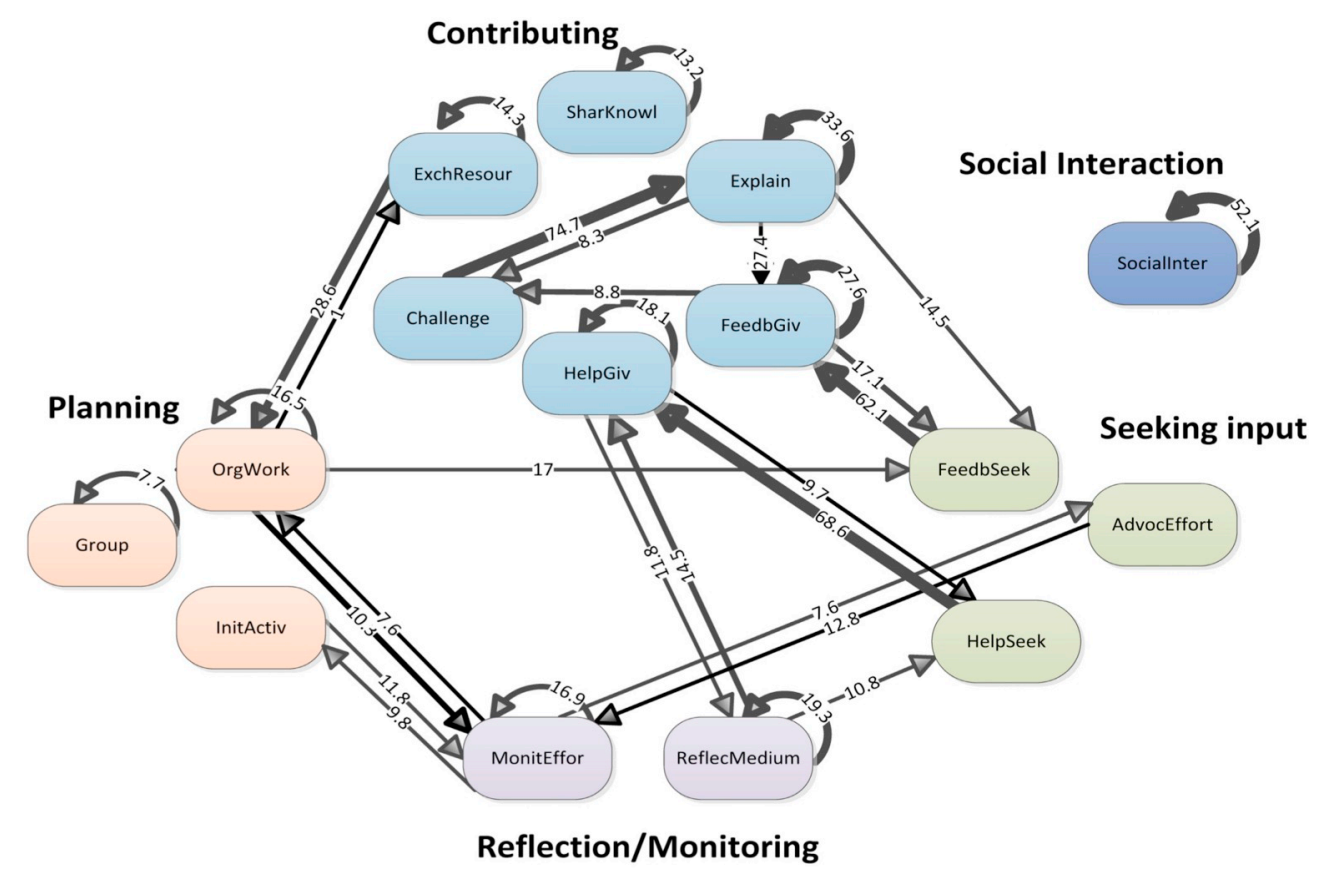

Fig. 4. Behavioral transition diagram for the IECS condition.

$52.1 \%$ of the occurrences of Social interaction on average.

Comparison of the behavioral transition diagrams for the IECS and CS conditions shows the collaborative patterns of behavior to be relatively similar. One difference that stands out is that the students in the IECS condition are more likely to post Explaining utterances following Challenging comments than the students in the CS condition (74.7\% versus 48.1\%). Another difference is that the dyads in the IECS condition tended to post more Explaining (Explain) contributions following Feedback giving (FeedbGiv) (27.4\%), whereas the dyads in the CS condition tended to post more Feedback giving (FeedbGiv) contributions following Explaining (Explain) comments (16.5\%). 


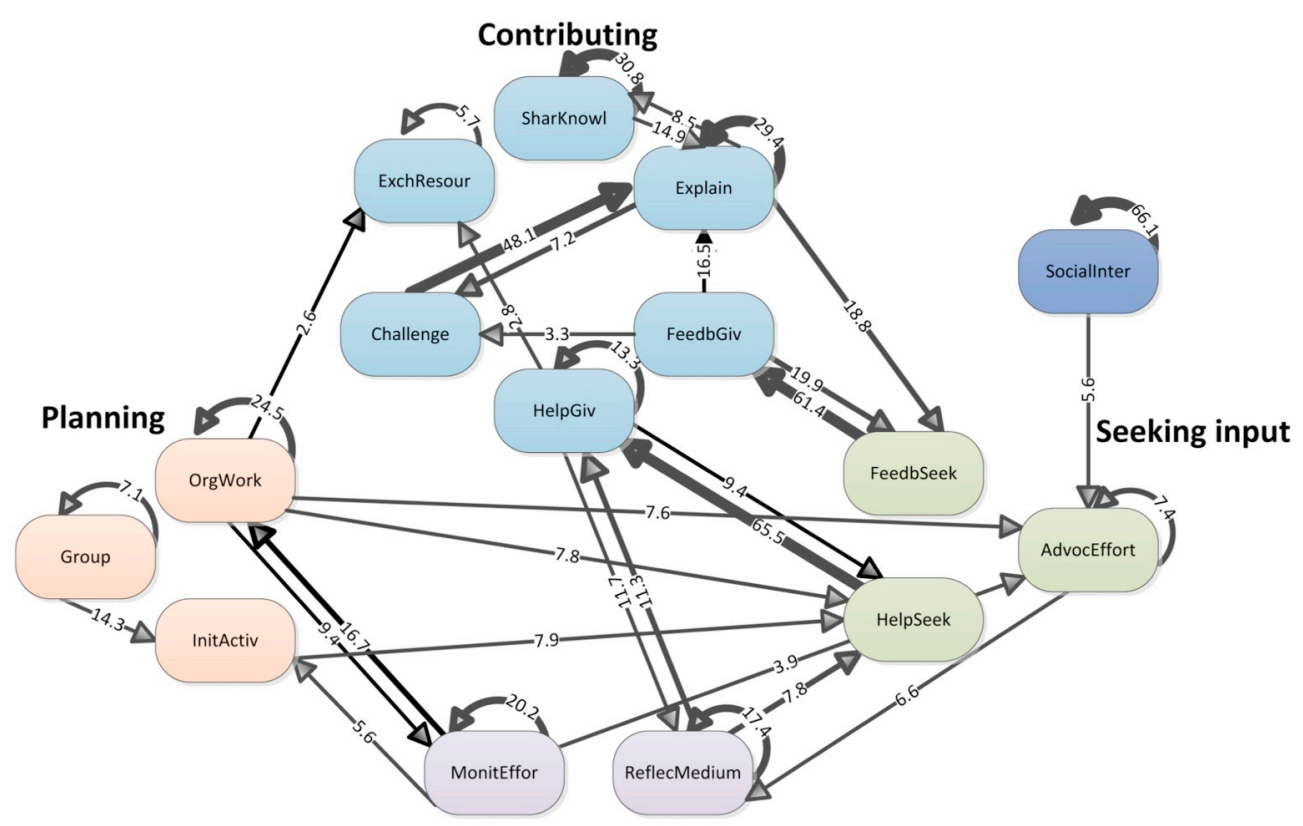

Reflection/Monitoring

Fig. 5. Behavioral transition diagram for the CS condition.

To determine if the differences between the behavioral patterns for the IECS versus CS conditions were statistically significant, the effect sizes were calculated and presented as transformed kappas $\left(\mathrm{k}^{\prime}\right)$; the direction and magnitude of the differences were then examined (Wampold \& Kim, 1989). For each dyad, we calculated the transformed kappa for 47 out of 225 possible transitions. As it was mentioned above, a total of 47 transitions were selected on the basis of the criterion of at least 10 or higher percentage indication of the conditional probabilities of transitions in either the IECS or the CS condition.

The results of a 2 (conditions) $\times 47$ (behavioral transitions) ANOVA revealed only four statistically significant differences between the IECS and the CS conditions (see Table 8). The IECS condition showed significantly more frequent Challenging $\rightarrow$ Explaining transitions $(F(1,34)=5.52, p<.05)$ and Explaining $\rightarrow$ Feedback giving transitions $(F(1,34)=6.48, p<.05)$ than the CS condition but statistically less frequent Sharing knowledge $\rightarrow$ Explaining $(F(1,34)=4.49, p<.05)$ and Feedback Giving $\rightarrow$ Explaining $(F$ $(1,34)=11.75, p<.01)$ than the CS condition.

The following excerpts illustrate these four transition types.

\section{Challenge $\rightarrow$ Explain}

vp8405: but then my question to you: why does better agriculture and more food increase their wealth on the long term? vp8406: yeah, in our driving part we also said that economic growth is a problem. so maybe explain more in driving part the economic growth means too much commercial waste.

Table 8

Means, standard deviations, and outcomes of univariate tests of significance for four transformed kappas showing statistically different patterns of collaborative behavior for two conditions.

\begin{tabular}{|c|c|c|c|c|c|}
\hline \multirow{2}{*}{ Behavioral transitions } & \multicolumn{2}{|l|}{ IECS } & \multicolumn{2}{|l|}{ CS } & \multirow[t]{2}{*}{$F$} \\
\hline & $\mathrm{M}$ & SD & M & SD & \\
\hline Challenge $\rightarrow$ Explaining & 0.71 & 0.23 & 0.41 & 0.48 & 5.52 \\
\hline Sharing knowledge $\rightarrow$ Explaining & -0.49 & 0.61 & -0.05 & 0.57 & $4.49^{\prime}$ \\
\hline Explaining $\rightarrow$ Feedback giving & 0.03 & 0.15 & -0.26 & 0.47 & 6.48 \\
\hline Feedback giving $\rightarrow$ Explaining & -0.28 & 0.34 & 0.09 & 0.31 & 11.75 \\
\hline
\end{tabular}

A negative transformed kappa shows the probability of subsequent collaborative behavior following antecedent collaborative behavior to be less than expected by chance.

IECS = intercultural enriched collaboration script.

$\mathrm{CS}=$ general collaboration script.

* Significant at $p<.05$.

** Significant at $p<.01$. 
Explaining $\rightarrow$ Feedback giving

vp8411: Rivers are running dry, water levels drop because of overpumping. Either way, a driving force that is not very different, in my opin[i]on, from food or timber shortages.

vp8412: I think I forgot things like building a dam and so on. So now I agree.

Feedback giving $\rightarrow$ Explaining

vp8408: Okay. The converse means the opposite.

vp8407: so I was mentioning organisms which live deep in the woods of fragmented areas would be pushed further in as the edge of the forest increases.

Sharing knowledge $\rightarrow$ Explaining

vp8420: in ppt, the impact is about health, culture, economy.

vp8421: fire risk is more of an impact, I suppose...you remember in the movie, there was one part when the man said because there was no frost that year it's a sign of fires to come meaning because of the change, the immediate impact is fire.

\subsection{Online collaborative learning performance}

No significant differences were found between the IECS and CS conditions when the means for learning performance were examined: IECS condition $M=2.78(S D=0.45)$ and CS condition $M=2.81(S D=0.30), F=0.06 ; p=.81$.

\section{Discussion}

With regard to our first research question, namely Does the effect of an interculturally-enriched collaboration script (IECS) for culturally heterogeneous groups of students working in a CSCL environment on the students' attitudes towards online collaboration differ from that of a general collaboration script (CS)?, our results showed the students at the beginning of the study in both conditions to have relatively positive attitudes towards online collaboration on average (mean scores greater than 3.6 along a 5-point Likert scale). Following completion of the experiment (i.e., at posttest), the students in the IECS condition showed an even more positive change in attitudes towards online collaboration than the CS condition. With the support of the IECS instructions at the start of the collaboration process (i.e., for the creation and exchange of personal profiles) and through the remainder of the collaboration process on how to collaborate with each other, it may be that the students in the IECS condition did not experience the same challenges and barriers to the same extent as the students in the CS condition where only limited instructions were provided. And as a result of this facilitation and group experience, the students in the IECS condition may have developed an even more positive attitude towards online collaboration.

The results of previous research indicate that the cultural orientations of learners shape their perceptions of working in groups: learners with a more collectivist orientation feel that they perform better in a group than learners with a more individualist orientation (Chan \& Watkins, 1994; Stepanyan, Mather, \& Dalrymple, 2014; Zhong, Liu, \& Lim, 2008). Other findings suggest the opposite, namely that students from collectivist cultures tend to be less motivated to participate in online collaboration than students from individualist cultures (MacLeod et al., 2017; Wang, 2007). It is argued by some that online forms of collaborative learning focus largely on conflict-oriented behavior between the collaborating partners, which is less compatible with a collectivist orientation towards interacting and learning in a group than with an individualist orientation (Anakwe \& Christensen, 1999; Gu et al., 2017; Oetzel, 1999; Phuong-Mai, Terlouw, \& Pilot, 2005, 2006; Uzuner, 2009). For example, the trust development of virtual multicultural groups, as one of contributing factors to the students' attitudes towards CSCL, shows instability and keeps decreasing over time, while members of monocultural groups trust each other more over time due to mostly language, values and habitual behavior (Cheng et al., 2016). In future investigations, it might be possible to explore what types of students, with what cultural orientations benefit most from the IECS support to engage in a productive debate and to critique each other's contributions by instructing them to take the time to fully understand their partner's contributions and think about the best way to respond (e.g., give specific feedback, feel free to disagree, advance one's reasoning).

With regard to our second research question concerned with categories and patterns of collaborative behavior, namely Does the effect of an interculturally-enriched collaboration script (IECS) for culturally heterogeneous groups of students working in a CSCL environment on the students' online collaborative learning behavior differ from that of a general collaboration script (CS)?, the students in the IECS condition tended to display a higher frequency of Initiating activities and Challenging behavior than the students in the CS condition but a lower frequency of Organizing work, Exchanging resources, Sharing knowledge, and Social interaction than the students in the CS condition (see Table 7). These differences can presumably be attributed to specific aspects of the scripts in the different conditions and the IECS instructions in particular. During the problem-solving phase of the collaborative learning task, the IECS instructions encouraged students with an individualist orientation to share ideas and information as much as possible, to critically assess their partners' contributions, and to allow their partners adequate time to respond; similarly, the IECS instructions encouraged students with a collectivist orientation to feel free to disagree with their partners, be as direct as possible, and be specific. These instructions presumably led to more challenging behavior and initiation of activities to solve the task in the IECS condition while students in the CS condition were relatively more concerned with organizing, exchanging, and off-task activities. Further research is needed to unravel the exact influence of IECS instructions on the individual behavior of students with a collectivist and individualist orientation. A further study could compare the students with a collectivist orientation in the IECS condition with the students with a 
collectivist orientation in the CS condition in terms of their collaborative behavior, social and cognitive changes. The same comparison needs to be done between the students with an individualist orientation in the IECS and CS conditions.

We also found a significantly lower frequency of Sharing knowledge and Social interaction in the IECS condition compared to the CS condition. The students in the IECS condition showed a more "critical discourse" and the students in the CS condition showed a more "cumulative discourse." According to Arvaja, Häkkinen, Eteläpelto, and Rasku-Puttonen (2003), in critical discourse "statements and suggestions are offered for joint consideration. These are then challenged and counter-challenged with justifications and alternative hypotheses" (p. 2). A cumulative discourse is characterized by the pooling of resources and sharing of existing knowledge and information to "build positively but uncritically on what the other has said, thus constructing common knowledge by accumulation" (p. 2). The present findings suggest that students are predisposed towards a cumulative discourse and thus to share existing information and knowledge with each other rather than to make assertions, raise questions, and challenge each other unless they are explicitly encouraged to do this, which would be in line with the results of previous studies (e.g., Andriessen, 2006; Curtis \& Lawson, 2001; Ozturk \& Hodgson, 2017).

With regard to the sequential pattern of the students' behavior when working in a CSCL environment, all of the noticeable differences between the two conditions involved the Contributing category of behavior in one way or another (see Table 8 and Figs. 4 and 5). Overall, the student dyads in both conditions interacted through a negotiation of meaning and clarification style of discussion. As already pointed out, the students in the IECS condition demonstrated more critical discussion than the students in the CS condition. This entailed Challenging the contributions of others and Explaining and/or elaborating on input. In the CS condition, uncritical joint knowledge sharing was more characteristic than critical discussion. More detailed research on the particular behavioral patterns of Challenging $\rightarrow$ Explaining and Sharing knowledge $\rightarrow$ Explaining is nevertheless called for in order to foster students engagement in "high-level" collaboration processes. From a cognitive perspective on collaborative learning (King, 1997; Kirschner, Sweller, Kirschner, \& Zambrano, 2018), these behavioral patterns seem to affect students' cognitive structures. Identifying the mechanisms of these behavioral patterns would allow to engage online group members in a critical but constructive discussion with each other which could lead to greater quality of learning (Hathorn \& Ingram, 2002; Mende, Proske, Körndle, \& Narciss, 2017).

Also with respect to the main Contributing category of collaborative behavior, relatively more Explaining $\rightarrow$ Feedback Giving behavioral transitions were observed in the IECS condition than in the CS condition but more Feedback Giving $\rightarrow$ Explaining transitions in the CS condition than in the IECS condition. These behavioral patterns represent different forms of reflective behavior and distinct processes of developing a shared understanding among the collaborating students in the two conditions. The IECS condition, in particular, appeared to foster more frequent attempts to elaborate and explain one's position followed by the provision of feedback on the position advanced. In the CS condition, feedback on a proposal was usually expressed in the form of consent, which was then followed by elaboration or explanation to make sure that both collaborative partners were "on the same page." In further more detailed analyses of these and other patterns of interaction, the roles of reflection and just how shared understanding is established between the partners should be considered. For the reason that reflection, peer feedback, and the process of how perceived shared understanding is being developed among collaborating students have been regarded as important for group's social and cognitive performance (Borge, Ong, \& Rosé, 2018; Korsager \& Slotta, 2015; Phielix, Prins, \& Kirschner, 2010).

Turning to our third research question, namely Does the effect of an interculturally-enriched collaboration script (IECS) for culturally heterogeneous groups of students working in a CSCL environment on the students' learning performance differ from that of a general collaboration script (CS)?, comparable scores were found for the DPSIR assignment and the use of task-related concepts in the Diagrammer tool, Cowriter tool, and Chat tool. However, the dyads in the IECS condition used concepts related to the solutions (Responses category) to the environmental problem more frequently in the Cowriter tool than dyads in the CS condition. This was the only difference in learning performance found between the two conditions. Learning the DPSIR framework was one of the desired outcomes. If students' prior knowledge of the DPSIR framework is zero, students' final learning performance score related to DPSIR could be regarded as their learning gain.

Previous research on CSCL has shown both individual and group learning outcomes to depend on the quality of the collaboration (Chen, Wang, Kirschner, \& Tsai, 2018; Lipponen, 2002). As already discussed, the students in the IECS and CS conditions exhibited largely comparable categories and patterns of online collaborative behavior. The dyads in the IECS condition nevertheless showed relatively more "challenging and explaining/elaborating" interactions than the dyads in the CS condition who showed more uncritical "joint sharing of knowledge and explanation/elaboration" interactions. Both types of interactions have been shown to be conducive to learning but to imply different levels of engagement in the collaboration process. And previous research has shown that learning is particularly likely to occur when the collaborating students engage in constructive argumentation (i.e., critique, challenging of positions, and attainment of synthesis via discussion) (Andriessen, Baker, \& Suthers, 2003; Cho \& Jonassen, 2002; Schwartz, 2018). Despite the different patterns of collaboration found in the different conditions in our study, significant learning differences did not manifest themselves yet.

There are at least two explanations for the observed lack of significant learning performance differences in our study. First, the amount of time for collaboration and task performance was brief. It is possible that students need more training time to optimally benefit from a script like the IECS. Previous research suggests that the more often students interact on the basis of an external script, the stronger the possibility that it will lead to an internalization of collaborative practices as collaboration skills and cognitive strategies (Fischer et al., 2013; Kollar, Fischer, \& Slotta, 2007). A longer training procedure with the IECS could make it more likely that the differences found in students' learning behavior would lead to higher learning performance as well. More extensive and possibly longitudinal research in the future should help us shed more light on the learning effects of using a script like the IECS to work in culturally heterogeneous groups within a CSCL environment.

The second possible explanation for the observed lack of significant learning performance differences between the conditions in 
our study concerns the measurement of group work. The assessment criteria that were used did not reveal if students worked better online in culturally heterogeneous groups, had increased awareness of cultural differences, or developed better collaboration skills. Future investigations should therefore include measures that are sufficiently sensitive to reveal individual social and cognitive growth (e.g., greater reflection, greater awareness of cultural diversity, ability to apply acquired knowledge and skills in diverse situations). A comparable assignment could be introduced as a transfer task, for example. This would enable individual students or groups of students to demonstrate whether they gained more knowledge and skills.

Some questions remain about the use of the I-C cultural orientation to determine the cultural backgrounds of the students in our study and the heterogeneity of the CSCL dyads. Although a student coming from a collectivist country can be assumed to be more likely to hold collectivist values and norms, the individual student may nevertheless exhibit certain individualist patterns of behavior due to prior exposure (i.e., travel, work) and learning on the basis of this or other experiences. It is also possible that only students with more individualist orientations within the existing variety of orientations choose to study abroad and that the differences between the individualist and collectivist groups in our study were not as large as might be expected on the basis of Hofstede's I-C orientations. Conclusions based on international populations of students must thus be interpreted with caution as they may not be completely applicable to peers residing in the native country. As pointed out by Vijver and Leung (1997): "cross-cultural studies often involve highly dissimilar groups. Consequently, groups can differ in many background characteristics, only some of which are relevant to the topic studied" (p. 32).

In a similar vein, it can be argued that the similarities between international students along Hofstede's I-C cultural orientation may be greater (e.g., the similarities between some Asian and South American students) than those along other dimensions, such as Power Distance or Uncertainty Avoidance. That is, cultures that are similar in terms of an individualist or collectivist orientation may still vary with respect to the behavior of individuals and discussion styles. For example, Danish and the U.S. culture seem to be similar with respect to individualist cultural orientation (Hofstede et al., 2010), but may still differ with respect to, for instance, level of sociability, intrinsic motivation, social interdependence, modesty in presenting ideas and sharing information (Bannon, 1995; MacLeod et al., 2017; Weinberger et al., 2007). The present findings should thus be verified using a larger sample and possibly other cultural frameworks (e.g., measures of analytic/holistic reasoning, see Choi and Nisbett (2000); seven-dimension framework for understanding cultural diversity, see Trompenaars (1993)). Accounting for all cultural factors is very desirable, but it was not feasible within the scope of the present study. There are also studies showing personal features to prevail over cultural background in influencing the efficiency of intercultural collaboration (e.g., Ting-Toomey et al., 2001). Although some scholars have argued, cultural differences cannot always be reduced to individual differences (see for a review, Na et al., 2010).

\section{Conclusion and implications}

Cultural background influences a student's attitude towards collaboration with peers and the student's level of engagement in the activities needed for collaborative problem solving. The present study investigated how cultural differences can be bridged within an CSCL environment. To this end, an interculturally enriched collaboration script was developed to facilitate and guide the online intercultural interaction process. Results show that the individualist-collectivist cultural orientation of students can provide an indication of how they will collaborate given their cultural backgrounds. Fostering social interaction (e.g., informal introductions, exchange of personal profiles) and encouraging critical discussion (e.g., concrete feedback, time to reflect) via an interculturally enriched collaboration script but also a general collaboration script can effectively scaffold online collaboration to improve group dynamics. Providing a specified sequence of events for the collaborating students to follow as part of the script instructions effectively minimized the amount of effort required to coordinate the collaborative learning process. Script instructions tailored to the individualist or collectivist cultural orientations of the students working collaboratively may thus promote greater rapport, greater engagement in productive debate, and greater convergence on the collaborative learning activities. Students' awareness of existing differences in communication styles can be heightened with the help of special features of CSCL tools (e.g., adaptive scripting as developed by Gweon, Rosé, Zaiss, and Carey (2006)) and by providing examples of such differences or case transcripts illustrating such differences (Kim \& Bonk, 2002). Furthermore, machine learning techniques can be applied to identify potential or actual problems arising from the intercultural CSCL context. A CSCL system can be designed to provide scaffolds that are triggered by the automated analysis of the online CSCL interaction. The system can monitor collaboration behaviors that are not conducive for productive group work (e.g., silent too long, one collaborator too overbearing, team stuck/not making a decision; no sufficient elaboration on one's own or partner's reasoning). On the basis of student inputs (e.g., eye gaze; verbal conversations by taking advantage of automated speech recognition technology) the system intervenes by giving prompts on an as-needed basis to get the team member(s) back on track. In other words, a dynamic adaptive scaffolding approach to fostering intercultural CSCL can be adopted to create context sensitive collaborative scripts when and as needed (Rosé, Fischer, \& Chang, 2007; Wang, Kollar, \& Stegmann, 2017).

The findings of this study and the ingredients of the IECS could provide the basis for recommending teaching strategies to increase the effective use of intercultural CSCL in their courses. The strategies can be realized via explicit instruction (e.g., oral presentation by the teacher, handouts) or via collaboration scaffolds embedded in the collaborative learning environment. The following strategies are proposed: (1) aligning study tasks and preparing learning activities to be carried out by culturally diverse groups of learners in CSCL; (2) continuous facilitating and monitoring of CSCL processes to foster the efficient exchange and integration of information in an intercultural CSCL group; (3) assessing student learning and efficacy of the instructional support to see if the expected positive effects have been achieved and can help the teachers apply the scaffolding in other intercultural CSCL settings when needed. These strategies are described below in more detail: 
1. Aligning study tasks and preparing learning activities. When incorporating intercultural CSCL into course activities, make sure that the choice of CSCL is justified and the added value and relevance of CSCL thus made clear to the students. Teachers should identify the expectations and preferences of the students for working in an intercultural CSCL group and align the study tasks with this information in addition to learning objectives. The greater the cultural gap between the students in a group, the greater the probability of communication difficulties, misunderstandings, conflicts, and problems with the coordination of activities, yet potentially rewarding experience.

2. Continuous facilitating and monitoring of CSCL processes. Teachers should consider moderating group discussions to assess the quality of the ongoing collaboration process, contribute to some conversations in order to stimulate more extensive discussion, keep the group focused, and/or provide feedback. Instructional scaffolds should be used as necessary to encourage students with a largely individualist orientation to critically assess the contributions of others, and to allow their partners adequate time to then respond; students with a more collectivist orientation should be encouraged to also critically assess the contributions of others, feel free to disagree with others, be as direct and specific as possible in their feedback and responding, and raise questions.

3. Assessing student learning and efficacy of the instructional support. Upon completion of the CSCL task, teachers should assess the quality of the learning process, the learning outcomes, and the interrelations between the two. Students should be asked to reflect upon the collaboration experience. This can be done with regard to what they have discovered about themselves, their culture, how they are perceived by students from other cultures, how they - themselves — perceive students from other cultures, their achieved performance, and their satisfaction with the collaboration process.

Last but not least, it is known that students from various cultures can have different perceptions and procedural knowledge of how to collaborate and learn together. CSCL methodologies should be developed to detect, manage, and bridge those differences. In the present research, an interculturally-enriched collaboration script was found to be needed and introduced for this purpose.

\section{Declarations of interest}

None.

\section{References}

Adler, P., Heckscher, C., \& Prusak, L. (2011). Building a collaborative enterprise. Harvard Business Review, 89(7-8), 94-101. July-August 2011. Retrieved from https:// hbr.org/2011/07/building-a-collaborative-enterprise.

Al-Harthi, A. S. (2005). Distance higher education experiences of Arab Gulf students in the United States: A cultural perspective. International Review of Research in Open and Distance Learning, 6(3), 1-14.

Anakwe, U. P., \& Christensen, E. W. (1999). Distance learning and cultural diversity: Potential users' perspective. The International Journal of Organizational Analysis, $7(3), 224-243$.

Andriessen, J. (2006). Arguing to learn. In R. K. Sawyer (Ed.). The Cambridge handbook of the learning sciences (pp. 443-460). New York: Cambridge University Press. Andriessen, J., Baker, M., \& Suthers, D. (2003). Arguing to learn. Confronting cognitions in computer-supported collaborative learning environments. Dordrecht: Kluwer.

Arvaja, M., Häkkinen, P., Eteläpelto, A., \& Rasku-Puttonen, H. (2003). Social processes and knowledge building in project-based face-to-face and networked interactions. In J. Bobry, \& A. Eteläpelto (Eds.). Collaboration and learning in virtual environments. Electronic publication. Retrieved from http://bibelot.jyu.fi/ julpu/ projektit/CAL/contents.pdf.

Bakeman, R., \& Gottman, J. M. (1997). Observing interaction: An introduction to sequential analysis (2nd ed.). Cambridge: Cambridge University Press.

Bakeman, R., \& Quera, V. (1995). Log-linear approaches to lag-sequential analysis when consecutive codes may and cannot repeat. Psychological Bulletin, 118(2), $272-284$.

Bannon, L. J. (1995). Issues in computer-supported collaborative learning. In C. O'Malley (Ed.). Computer supported collaborative learning (pp. 267-281). Berlin: Springer-Verlag.

Borge, M., Ong, Y. S., \& Rosé, C. P. (2018). Learning to monitor and regulate collective thinking processes. International Journal of Computer-Supported Collaborative Learning, 13(1), 61-92.

Carmien, S., Kollar, I., Fischer, G., \& Fischer, F. (2007). The interplay of internal and external scripts. In F. Fischer, I. Kollar, H. Mandl, \& J. M. Haake (Eds.). Scripting computer-supported learning - cognitive, computational, and educational perspectives (pp. 303-326). New York, NY: Springer.

Chan, Y. Y. G., \& Watkins, D. (1994). Classroom environment and approaches to learning: An investigation of the actual and preferred perceptions of Hong Kong secondary school students. Instructional Science, 22, 233-246.

Chang, T.-T., Wang, X., \& Lim, J. (2002). Cross-cultural communication, media and learning processes in asynchronous learning networks. Proceeding of: System Sciences, 2002. HICSS (pp. 113-122). Los Alamitos: IEEE Computer Society.

Chen, G. M., \& Starosta, W. J. (1998). A review of the concept of intercultural sensitivity. Human Communication, 1, 1-16.

Chen, J., Wang, M., Kirschner, P. A., \& Tsai, C. C. (2018). The Role of Collaboration, Computer Use, Learning Environments, and Supporting Strategies in CSCL: A Meta-Analysis. Review of Educational Research, 88(6), 799-843.

Cheng, X., Fu, S., Sun, J., Han, Y., Shen, J., \& Zarifis, A. (2016). Investigating individual trust in semi-virtual collaboration of multicultural and unicultural teams. Computers in Human Behavior, 62, 267-276.

Cho, K. L., \& Jonassen, D. H. (2002). The effects of argumentation scaffolds on argumentation and problem solving. Educational Technology Research and Development, $50(3), 5-22$.

Choi, I., \& Nisbett, R. E. (2000). Cultural psychology of surprise: Holistic theories and recognition of contradiction. Journal of Personality and Social Psychology, 79, 890-905.

Cox, T. H., Lobel, S. A., \& McLeod, P. L. (1991). Effects of ethnic group cultural differences on cooperative and competitive behavior on a group task. Academy of Management Journal, 34(4), 827-847.

Curtis, D. D., \& Lawson, M. J. (2001). Exploring collaborative online learning. Journal of Asynchronous Learning Networks, 5(1), $21-34$.

Dai, Y. (2019). Situating videoconferencing in a connected class for intercultural knowledge development: A comparative reflection approach. The Internet and Higher Education, 41, 1-10.

Duffy, T. M., \& Cunningham, D. J. (1996). 7. Constructivism: Implications for the design and delivery of instruction.

Economides, A. A. (2008). Culture-aware collaborative learning. Multicultural Education and Technology Journal, 2 (4), $243-267$.

Erkens, G. (2005). Multiple episode protocol analysis (MEPA). Version 4.10 softwareThe Netherlands: Utrecht University.

Erkens, G., \& Janssen, J. J. H. M. (2008). Automatic coding of dialogue acts in collaboration protocols. International Journal of Computer-Supported Collaborative Learning, 3(4), 447-470. 
Erkens, G., Jaspers, J., Prangsma, M., \& Kanselaar, G. (2005). Coordination processes in computer supported collaborative writing. Computers in Human Behavior, 21(3), 463-486.

Ess, C., \& Sudweeks, F. (2005). Culture and computer-mediated communication: Toward new understandings. Journal of Computer-Mediated Communication, 11(1), 179-191.

Fischer, F., Kollar, I., Stegmann, K., \& Wecker, C. (2013). Toward a script theory of guidance in computer-supported collaborative learning. Educational Psychologist, $48(1), 56-66$.

Fortuin, K. P. J., van Koppen, C. S. A., \& Leemans, R. (2011). The value of conceptual models in coping with complexity and interdisciplinarity in environmental sciences education. Bioscience, 61(10), 802-814.

Frambach, J. M., Driessen, E. W., Beh, P., \& van der Vleuten, C. P. (2014). Quiet or questioning? Students' discussion behaviors in student-centered education across cultures. Studies in Higher Education, 39(6), 1001-1021.

Frederiksen, C. H. (1999). Learning to reason through discourse in a problem-based learning group. Discourse Processes, 27(2), 135-160.

Fussell, S. R., \& Setlock, L. D. (2014). Computer-mediated communication. In T. Holtgraves (Ed.). Handbook of language and social psychology (pp. 471-490). Oxford, UK: Oxford University Press.

Goncale, J. A., \& Staw, B. M. (2006). Individualism-collectivism, and group creativity. Organizational Behavior and Human Decision Processes, 100, 96-109.

Gouveia, V. V., Clemente, M., \& Espinosa, P. (2003). The horizontal and vertical attributes of individualism and collectivism in a Spanish population. The Journal of Social Psychology, 143(1), 43-63.

Gu, X., Wang, H., \& Mason, J. (2017). Are they thinking differently: A cross-cultural study on the relationship of thinking styles and emerging roles in computersupported collaborative learning. Journal of Educational Technology \& Society, 20(1), 13.

Gudykunst, W. B., Matsumoto, Y., Ting-Tooney, S., Nishida, T., Kim, K., \& Heyman, S. (1996). The influence of cultural individual-collectivism, self-construals, and individual values on communication styles across cultures. Human Communication Research, 22, 510-543.

Gunawardena, C. N., Walsh, S. L., Reddinger, L., Gregory, E., Lake, Y., \& Davies, A. (2002). Negotiating 'face' in a non-face-to-face learning environment. In F. Sudweeks, \& C. Ess (Eds.). Proceedings of the third conference on cultural attitudes towards technology and communication 2002 (pp. 89-106). Murdoch, WA, Australia: School of Information Technology, Murdoch University.

Gunawardena, L., Lowe, C., \& Anderson, T. (1997). Interaction analysis of a global on-line debate and the development of a constructivist interaction analysis model for computer conferencing. Journal of Educational Computing Research, 17(4), 395-429.

Gweon, G., Rosé, C. P., Zaiss, Z., \& Carey, R. (2006). Providing support for adaptive scripting in an on-line collaborative learning environment. Proceedings of CHI 06: ACM conference on human factors in computer systems. New York: ACM Press.

Hall, E. (1990). Understanding cultural differences. Yarmouth, ME: Intercultural Press.

Hämäläinen, R., Oksanen, K., \& Häkkinen, P. (2008). Designing and analyzing collaboration in a scripted game for vocational education. Computers in Human Behavior, 24(6), 2496-2506.

Hampden-Turner, C., \& Trompenaars, F. (1997). Mastering the infinite game: How Asian values are transforming business practice. Oxford, England: Capstone.

Hathorn, L. G., \& Ingram, A. L. (2002). Online collaboration: Making it work. Educational Technology, 42(1), 33-40.

Hod, Y., Sagy, O., \& Kali, Y. (2018). The opportunities of networks of research-practice partnerships and why CSCL should not give up on large-scale educational change. International Journal of Computer-Supported Collaborative Learning, 1-10.

Hofstede, G. (1991). Cultures and organizations: Software of the mind. London: McGraw-Hill.

Hofstede, G. (1997). Culture and Organisations: Software of the Mind: Intercultural Cooperation and its importance for Survival. McGraw-Hill.

Hofstede, G. (2001). Cultural consequences: Comparing values, behaviors, institutions, and organizations across nations. United States of America: Sage Publications.

Hofstede, G., Hofstede, G., \& Minkov, M. (2010). Cultures and organizations: Software of the mind (3rd ed.). USA: McGraw-Hill.

Hollander, M., Wolfe, D. A., \& Chicken, E. (2013). Nonparametric statistical methods. Vol. 751. John Wiley \& Sons.

Culture, leadership, and organizations. In R. J. House, P. J. Hanges, M. Javidan, P. W. Dorfman, \& V. Gupta (Eds.). Sage publications: The GLOBE study of 62 societies.

Jaspers, J., Broeken, M., \& Erkens, G. (2004). Virtual Collaborative Research Institute (VCRI) (version 2.0). Utrecht: Onderwijskunde Utrecht, ICO/ISOR.

Johnson-Laird, P. N. (2013). Mental models and cognitive change. Journal of Cognitive Psychology, 25(2), $131-138$.

Kapur, M. (2008). Productive failure. Cognition and Instruction, 26(3), 379-424.

Kim, K.-J., \& Bonk, J. C. (2002). Cross-cultural comparisons of online collaboration. Journal of Computer-Mediated Communication, 8(1), 1-12.

King, A. (1997). ASK to THINK-TELL WHY: A model of transactive peer tutoring for scaffolding higher level complex learning. Educational Psychologist, 32(4), 221-235.

Kirschner, P. A., Sweller, J., Kirschner, F., \& Zambrano, J. (2018). From cognitive load theory to collaborative cognitive load theory. International Journal of ComputerSupported Collaborative Learning, 1-21.

Kollar, I., Fischer, F., \& Hesse, F. (2006). Computer-supported cooperation scripts-A conceptual analysis. Educational Psychology Review, 18(2), 159-185.

Kollar, I., Fischer, F., \& Slotta, J. D. (2007). Internal and external scripts in computer-supported collaborative inquiry learning. Learning \& Instruction, 17(6), 708-721.

Kolodner, J. L. (2007). The roles of scripts in promoting collaborative discourse in learning by design. In F. Fischer, I. Kollar, H. Mandl, \& J. M. Haake (Eds.). Scripting (Computer-Supported) Collaborative Learning (pp. 237-262). Boston, (MA): Springer (US).

Korsager, M., \& Slotta, J. D. (2015). International peer collaboration to learn about global climate changes. International Journal of Environmental and Science Education, 10(5), 717-736.

Kreijns, K., Kirschner, P. A., \& Jochems, W. (2003). Identifying the pitfalls for social interaction in computer-supported collaborative learning environments: A review of the research. Computers in Human Behavior, 19(3), 335-353.

Lal, V.. Cultural Difference and its influence on learning with computer-based technologies in schools. (2002). Retrieved Nov.12 2011 http://www.effectsproject.uts.edu.au/ project_papers/3_vijendra_lal.pdf from.

Landis, J. R., \& Koch, G. G. (1977). The measurement of observer agreement for categorical data. Biometrics, 33(1), 159-174.

Laurance, W. F., et al. (2012). Averting biodiversity collapse in tropical forest protected areas. Nature, 489, 290-294. https://doi.org/10.1038/nature11318.

Lee, N. Y. L., \& Johnson-Laird, P. N. (2006). Are there cross-cultural differences in reasoning? In Proceedings of the 28th annual meeting of the Cognitive Science Society (pp. 459 - 464)Vancouver, BC: Cognitive Science Society0-9768318-2-1.

Lehtinen, E., Hakkarainen, K., Lipponen, L., Rahikainen, M., \& Muukkonen, H. (1999). Computer-supported collaborative learning: A review of research and development. The J.H.G.I Giesbers reports on education. 10. Netherlands: University of Nijmegen, Department of Educational Sciences.

Lim, J., \& Liu, Y. (2006). The role of cultural diversity and leadership in computer-supported collaborative learning: A content analysis. Information \& Software Technology, 48(3), 142-153.

Lipponen, L. (2002). Exploring foundations for computer-supported collaborative learning. In G. Stahl (Ed.). Computer support for collaborative learning: Foundations for a CSCL community (pp. 72-81). Hillsdale, NJ: Lawrence Erlbaum.

Lizzio, A., Wilson, K., \& Simons, R. (2002). University students' perceptions of the learning environment and academic outcomes: Implications for theory and practice. Studies in Higher Education, 27(1), 27-52.

Lovelace, K., Shapiro, D. L., \& Weingart, L. R. (2001). Maximizing Cross-Functional New Product Teams' Innovativeness and Constraint Adherence: A Conflict Communications Perspective. Academy of Management Journal, 44(4), 779-793.

MacLeod, J., Yang, H. H., \& Xiang, Z. (2017). Understanding college students' intrinsic motivation and social interdependence in intercultural computer-supported collaborative learning between USA and China. The Asia-Pacific Education Researcher, 26(3-4), $205-217$.

Markus, H. R., \& Kitayama, S. (1991). Culture and the self: Implications for cognition, emotion, and motivation. Psychological review, 98(2), 224.

McSweeney, B. (2002). Hofstede's model of national cultural differences and their consequences: A triumph of faith-a failure of analysis. Human relations, 55(1), 89-118.

Mende, S., Proske, A., Körndle, H., \& Narciss, S. (2017). Who benefits from a low versus high guidance CSCL script and why? Instructional Science, 45(4), 439-468.

Mittelmeier, J., Rienties, B., Tempelaar, D., \& Whitelock, D. (2018). Overcoming cross-cultural group work tensions: Mixed student perspectives on the role of social relationships. Higher Education, 75(1), 149-166. 
Morse, K. (2003). Does one size fit all? Exploring asynchronous learning in a multicultural environment. Journal of Asynchronous Learning Networks, 7(1), 37-55.

Murray-Johnson, L., Witte, K., Liu, W. Y., Hubbell, A. P., Sampson, J., \& Morrison, K. (2001). Addressing cultural orientations in fear appeals: Promoting AIDSprotective behaviors among Mexican immigrant and African American adolescents and American and Taiwanese college students. Journal of Health Communication, 6, 335-358.

Na, J., Grossmann, I., Varnum, M. E. W., Kitayama, S., Gonzalez, R., \& Nisbett, R. E. (2010). Cultural differences are not always reducible to individual differences. PNAS Proceedings of the National Academy of Sciences of the United States of America, 107, 6192-6197.

Nezhina, T., \& Ibrayeva, A. R. (2008). Explaining the role of culture and traditions in functioning of civil society organizations in Kazakhstan.

Nguyen, D. T., \& Fussell, S. R. (2012). How did you feel during our conversation?: retrospective analysis of intercultural and same-culture instant messaging conversations. ACM. (pp. 117-126).

Nisbett, R. E. (2003). The Geography of thought. How asians and westerners think differently... and why. 5-47.

Nisbett, R. E., \& Norenzayan, A. (2002). Culture and cognition. In D. L. Medin (Ed.). Stevens' handbook of experimental psychology: Cognition (pp. 561-597). New York: Wiley.

Nisbett, R. E., Peng, K., Choi, I., \& Norenzayan, A. (2001). Culture and systems of thought: Holistic vs. analytic cognition. Psychological Review, 108, 291-310.

Nistor, N., Lerche, T., Weinberger, A., Ceobanu, C., \& Heymann, O. (2014). Towards the integration of culture into the Unified Theory of Acceptance and Use of Technology. British Journal of Educational Technology, 45(1), 36-55.

Oetzel, J. G. (1999). The influence of situational features on perceived conflict styles and self-construals in work groups. International Journal of Intercultural Relations, 23(4), 679-695.

Oetzel, J. G. (2001). Self-construals, communication processes and group outcomes in homogeneous and heterogeneous groups. Small Group Research, 32(1), 19-54.

Oetzel, J. G., Ting-Toomey, S., Yokochi, Y., Masumoto, T., \& Takai, J. (2000). A typology of facework behaviors in conflicts with best friends and relative strangers. Communication Quarterly, 4, 397-419.

Organization for Economic Co-operation and Development (2015). PISA 2015: PISA results in focus. Retrieved from https://www.oecd.org/pisa/pisa-2015-results-infocus.pdf.

Ouamani, F., Ben Saoud, N. B., \& Ben Ghézala, H. H. (2014). Management of socio-cultural knowledge using an ontology-based socio-cultural user profile in a computer-supported collaborative learning environment. Journal of Decision Systems, 23(1), 40-54.

Ozturk, T. H., \& Hodgson, V. (2017). Developing a model of conflict in virtual learning communities in the context of a democratic pedagogy. British Journal of Educational Technology, 48(1), 23-42.

P21 (2014). Partnership for 21st century learning: The 4Cs: Communication, collaboration, critical thinking, creativity. Retrieved from http://www.p21.org/storage/ documents/4csposter.pdf.

Perera, N., \& Wise, A. F. (2017). Beyond demographic boxes: Relationships between Students' cultural orientations and collaborative communication. Philadelphia, PA: International Society of the Learning Sciences.

Phielix, C., Prins, F. J., \& Kirschner, P. A. (2010). Awareness of group performance in a CSCL-environment: Effects of peer feedback and reflection. Computers in Human Behavior, 26(2), 151-161.

Phuong-Mai, N., Terlouw, C., \& Pilot, A. (2005). Cooperative learning vs Confucian heritage culture's collectivism: Confrontation to reveal some cultural conflicts and mismatch. Asia Europe Journal, 3(3), 403-419.

Phuong-Mai, N., Terlouw, C., \& Pilot, A. (2006). Culturally appropriate pedagogy: The case of group learning in a Confucian Heritage Culture context. Intercultural Education, 17(1), 1-19.

Ploetzner, R., Fehse, E., Kneser, C., \& Spada, H. (1999). Learning to relate qualitative and quantitative problem representations in a model-based setting for collaborative problem solving. Journal of the Learning Sciences, 8, 177-214.

Popov, V., Biemans, H. J. A., Brinkman, D., Kuznetsov, A., \& Mulder, M. (2013). Facilitation of computer-supported collaborative learning in mixed-versus sameculture dyads: Does a collaboration script help? The Internet and Higher Education, 19, 36-48.

Popov, V., Biemans, H. J. A., Kuznetsov, A. N., \& Mulder, M. (2014). Use of an interculturally enriched collaboration script in computer-supported collaborative learning in higher education. Technology, Pedagogy and Education, 23(3), 349-374.

Popov, V., Brinkman, D., Biemans, H. J. A., Mulder, M., Kuznetsov, A., \& Noroozi, O. (2012). Multicultural student group work in higher education: An explorative case study on challenges as perceived by students. International Journal of Intercultural Relations, 36(2), 302-317.

Popov, V., Noroozi, O., Barrett, J. B., Biemans, H. J. A., Teasley, S. D., Slof, B., \& Mulder, M. (2014). Perceptions and experiences of, and outcomes for, university students in culturally diversified dyads in a computer-supported collaborative learning environment. Computers in Human Behavior, 32, 186-200.

Prinsen, F. R., Volman, M. L. L., \& Terwel, J. (2007). Gender-related differences in computer-mediated communication and computer-supported collaborative learning. Journal of Computer Assisted Learning, 23(5), 393-409.

Reeder, K., Macfadyen, L. P., Roche, J., \& Chase, M. (2004). Negotiating cultures in cyberspace: Participation patterns and problematics (Doctoral dissertation, University of British Columbia).

Rosé, C., Fischer, F., \& Chang, C. (2007). Exploring the influence of culture on collaborative learning. Retrieved from http://www.cs.cmu.edu/ sfussell/CHI2007/ RoseAbstract.pdf.

Ross, N. (2004). Culture and cognition: Implications for theory and method. Sage.

Rummel, N., \& Spada, H. (2005). Learning to collaborate: An instructional approach to promoting collaborative problem solving in computer-mediated settings. Journal of the Learning Sciences, 14(2), 201-241.

Safarov, I. (2010). How can culture differences impact implementation of business strategies of German investors/entrepreneurs in Uzbekistan? WIUT.

Salas, E., Burke, C. S., Wilson-Donnelly, K. A., \& Fowlkes, J. E. (2004). Promoting effective leadership within multicultural teams: An event-based approach. In D. V. Day, S. J. Zaccaro, \& S. M. Halpin (Eds.). Leader development for transforming organizations (pp. 293-324). Mahwah, NJ: Lawrence Erlbaum Associates.

Salili, F. (1996). Accepting personal responsibility for learning. In D. A. Watkins, \& J. B. Biggs (Eds.). The Chinese learner: Cultural, psychological and contextual influences (pp. 85-105). Hong Kong: CERC and ACER.

Sandel, T. L., Buttny, R., \& Varghese, M. (2018). Online interaction across three contexts: An analysis of culture and technological affordances. Journal of Intercultural Communication Research, 1-20.

Schellens, T., Van Keer, H., De Wever, B., \& Valcke, M. (2007). Scripting by assigning roles: Does it improve knowledge construction in asynchronous discussion groups? International Journal of Computer-Supported Collaborative Learning, 2(2-3), 225-246.

Schoonenboom, J. (2008). The effect of a script and a structured interface in grounding discussions. International Journal of Computer-Supported Collaborative Learning, 3(3), 327-341.

Schwartz, B. B. (2018). Computer-supported argumentation and learning. In F. Fischer, C. E. Hmelo-Silver, S. R. Goldman, \& P. Reimann (Eds.). International handbook of the learning sciences (pp. 318-329). New York: Routledge.

Serçe, F. C., Swigger, K., Alpaslan, F. N., Brazile, R., Dafoulas, G., \& Lopez, V. (2011). Online collaboration: Collaborative behavior patterns and factors affecting globally distributed team performance. Computers in human behavior, 27(1), 490-503.

Setlock, L., Fussell, S., \& Neuwirth, C. (2004). Taking it out of context: Collaborating within and across cultures in face-to-face settings and via instant messaging. .

Shapiro, N. Z., \& Anderson, R. (1985). Toward an ethics and etiquette for electronic mail. Santa Monica: The Rand Corporation.

Shi, Y., Frederiksen, C. H., \& Muis, K. R. (2013). A cross-cultural study of self-regulated learning in a computer-supported collaborative learning environment. Learning and Instruction, 23, 52-59.

Slof, B., Erkens, G., Kirschner, P. A., Jaspers, J. G. M., \& Janssen, J. (2010). Guiding learners' online complex learning-task behavior through representational scripting. Computers in Human Behavior, 26, 927-939.

So, H.-J., \& Brush, T. A. (2008). Student perceptions of collaborative learning, social presence and satisfaction in a blended learning environment: Relationships and critical factors. Computers \& Education, 51(1), 318-336.

Sondergaard, M. (1994). Research note: Hofstede's consequences: A study of reviews, citations and replications. Organization Studies, $15(3), 447-456$. 
Stahl, G. (2010). Guiding group cognition in CSCL. International Journal of Computer-Supported Collaborative Learning, 5(3), 255-258.

Stahl, G. (2017). Essays in computer-supported collaborative learning. Lulu.com.

Stegmann, K., Weinberger, A., \& Fischer, F. (2007). Facilitating argumentative knowledge construction with computer-supported collaboration scripts. International Journal of Computer-Supported Collaborative Learning, 2(4), 421-447.

Stepanyan, K., Mather, R., \& Dalrymple, R. (2014). Culture, role and group work: A social network analysis perspective on an online collaborative course. British Journal of Educational Technology, 45(4), 676-693.

Sweller, J. (1988). Cognitive load during problem solving: Effects on learning. Cognitive science, 12(2), $257-285$.

Swigger, K., Hoyt, M., Serçe, F. C., Victor, V., \& Alpaslan, F. N. (2012). The temporal communication behaviors of global software development student teams. Computers in Human Behavior, 28, 384-392.

Tancig, S. (2009). Expert team decision-making and problem-solving: development and learning. Interdisciplinary Description of Complex Systems, 7, 106-116.

Tapanes, M. A., Smith, G. G., \& White, J. A. (2009). Cultural diversity in online learning: A study of the perceived effects of dissonance in levels of individualism/ collectivism and tolerance of ambiguity. The Internet and Higher Education, 12, 26-34.

Taras, V., Rowney, J., \& Steel, P. (2009). Half a century of measuring culture: Approaches, challenges, limitations, and suggestions based on the analysis of 121 instruments for quantifying culture. Journal of International Management, 5(14), 357-373.

Thompson, L., \& Ku, H. (2005). Chinese graduate students' experiences and attitudes toward online learning. Educational Media International, $42(1), 33-47$.

Thompson, L., \& Ku, H. Y. (2006). A case study of online collaborative learning. Quarterly Review of Distance Education, 7(4), 361-375.

Ting-Toomey, S., Oetzel, J. G., \& Yee-jung, K. (2001). Self-construal types and conflict management styles. Communication Reports, 14(2), 87-105.

Triandis, H. C. (1994). Cross-cultural industrial and organizational psychology. In M. D. Dunnette, \& L. Hough (Eds.). Handbook of industrial and organizational psychology (pp. 103-172). Palo Alto, CA: Consulting Psychology Press.

Triandis, H. C. (1995). New directions in social psychology. Individualism \& collectivism. Boulder, CO, US: Westview Press.

Trompenaars, F. (1993). Riding the waves of culture: Understanding cultural diversity in business. London: The Economist Books.

Uzuner, S. (2009). Questions of culture in distance learning: A research review. The International Review of Research in Open and Distance Learning, 10(3), 1-11.

Van Bruggen, J. M., Boshuizen, H. P. A., \& Kirschner, P. A. (2003). A cognitive framework for cooperative problem solving with argument visualization. In P. A. Kirschner, S. J. Buckingham-Shum, \& C. S. Carr (Eds.). Visualizing argumentation: Software tools for collaborative and educational sense-making (pp. 25-47). London: Springer.

Vatrapu, R. (2008). Cultural considerations in computer supported collaborative learning. Research and Practice in Technology Enhanced Learning, 3(2), 159-201.

Vatrapu, R., \& Suthers, D. (2007). Culture and computers: A review of the concept of culture and implications for intercultural collaborative online learning. In T. Ishida, S. R. Fussell, \& P. T. J. M. Vossen (Eds.). Intercultural Collaboration: Lecture Notes in Computer Science (pp. 260-275). Springer-Verlag.

Vijver, F. V. D., \& Leung, K. (1997). Methods and data analysis for cross-cultural research. Thousand Oaks, CA: Sage.

Voronov, M., \& Singer, J. A. (2002). The myth of individualism-collectivism: A critical review. Journal of Social Psychology, 142(4), 461-480.

Wallender, J. (2014). The common core state standards in American public education: Historical underpinnings and justifications. Delta Kappa Gamma Bulletin, 80(4),

Walther, J. B. (1997). Group and interpersonal effects in international computer-mediated collaboration. Human Communication Research, 23(3), 342-369.

Wampold, B. E. (1992). The intensive examination of social interactions. In T. R. Kratochwill, \& J. R. Levin (Eds.). Single-case research design and analysis: New directions for psychology and education (pp. 93-131). Hillsdale, NJ: Erlbaum.

Wampold, B. E. (1995). Analysis of behavior sequences in psychotherapy. In J. Siegfried (Ed.). Therapeutic and everyday discourse as behavior change: Towards a microanalysis in psychotherapy process research (pp. 189-214). Norwood, NJ: Ablex.

Wampold, B. E., \& Kim, K.-H. (1989). Sequential analysis applied to counseling process and outcome: A case study revisited. Journal of Counseling Psychology, 36, 357-364.

Wampold, B. E., \& Margolin, G. (1982). Nonparametric strategies to test the independence of behavioral states in sequential data. Psychological Bulletin, 92, 755-765.

Wang, M. (2007). Designing online courses that effectively engage learners from diverse cultural backgrounds. British Journal of Educational Technology, 38(2), 294-311.

Wang, X., Kollar, I., \& Stegmann, K. (2017). Adaptable scripting to foster regulation processes and skills in computer-supported collaborative learning. International Journal of Computer-Supported Collaborative Learning, 12(2), 153-172.

Weinberger, A. (2011). Principles of transactive computer-supported collaboration scripts. Nordic Journal of Digital Literacy, 6(3), $189-202$.

Weinberger, A., Clark, D. B., Hakkinen, P., Tamura, Y., \& Fischer, F. (2007). Argumentative knowledge construction in online learning environments in and across different cultures: A collaboration script perspective. Research in Comparative and International Education, 2(1), 68-79.

Weinberger, A., Marttunen, M., Laurinen, L., \& Stegmann, K. (2013). Inducing socio-cognitive conflict in Finnish and German groups of online learners by CSCL script. International Journal of Computer-Supported Collaborative Learning, 8(3), 333-349.

Woodrow, D. (2001). Cultural determination of curricula, theories and practices. Pedagogy, Culture and Society, 9(1), 5-27.

Yumiko, A., Yukihiro, M., \& Pitagan, F. B. (2018). Effects of synchronous CSCL on perceived social presence, satisfaction, and learning: Text versus video chat among EFL learners. Advanced Science Letters, 24(11), 8043-8046.

Zhong, Y., Liu, N., \& Lim, J. (2008). Effects of cultural orientation on attitude towards anonymity in e-collaboration. In G. León, A. Bernardos, J. Casar, K. Kautz, \& J. DeGross (Eds.). Open IT-based innovation: Moving towards cooperative IT transfer and knowledge diffusion (pp. 121-138). Boston: Springer.

Zhu, C. (2009). E-learning in higher education: Student and teacher variables in the Chinese and Flemish cultural context (PhD dissertation)Belgium: University of Ghent.

Zhu, C. (2013). The effect of cultural and school factors on the implementation of CSCL. British Journal of Educational Technology, 44(3), 484-501.

Zhu, C., Valcke, M., Schellens, T., \& Li, Y. (2009). Chinese Students' perceptions of a collaborative-learning environment and factors affecting their performance: Implementing a Flemish e-learning course in a Chinese educational context. Asia Pacific Education Review, 10(2), $225-235$. 